\title{
Separation of Hexane Isomers in ZIF-8 by Fixed Bed Adsorption
}

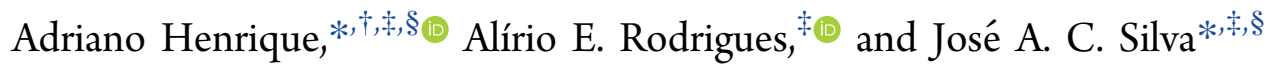 \\ ${ }^{\dagger}$ Laboratory of Separation and Reaction Engineering - Laboratory of Catalysis and Materials (LSRE/LCM), Department of \\ Chemical Engineering, Faculty of Engineering University of Porto, Rua Dr. Roberto Frias, S/N, 4200-465 Porto, Portugal \\ ${ }^{\ddagger}$ Laboratory of Separation and Reaction Engineering (LSRE), Associate Laboratory LSRE/LCM, Department of Chemical and \\ Biological Technology, Polytechnic Institute of Braganca, Campus de Santa Apolonia, 5300-857 Braganca, Portugal \\ ${ }^{\S}$ Centro de Investigação de Montanha (CIMO), Instituto Politécnico de Bragança, Campus de Santa Apolónia, $5300-253$ Bragança, \\ Portugal
}

\section{Supporting Information}

\begin{abstract}
The performance of porous metal organic framework ZIF-8 in the separation of all five hexane isomers ( $\mathrm{nC} 6,2 \mathrm{MP}, 3 \mathrm{MP}, 23 \mathrm{DMB}, 22 \mathrm{DMB}$ ) is evaluated through a series of multicomponent breakthrough adsorption experiments, at the temperatures of 373,423 , and $473 \mathrm{~K}$ and up to total hexane isomers pressure of 0.5 bar. The reported data show for all experiments the following sorption hierarchy: $\mathrm{nC} 6 \gg 2 \mathrm{MP}>3 \mathrm{MP} \gg 23 \mathrm{DMB}>22 \mathrm{DMB}$. At the temperature of $373 \mathrm{~K}$ and total hydrocarbon pressure of $0.5 \mathrm{bar}$ the mixture loading of hexane isomers can go up to $2.15 \mathrm{~mol} \cdot \mathrm{kg}^{-1}$. In addition, at the same temperature the selectivities measured by the ratio of the loadings between linear plus monobranched ( $\mathrm{nC6}, 2 \mathrm{MP}, 3 \mathrm{MP}$ ) relatively to the dibranched (23DMB, 22DMB) isomers range between 34-55. The results also show that the sorption of $\mathrm{nC} 6$ is equilibrium based in contrast with the sorption of branched isomers which is kinetically controlled. The dibranched isomer

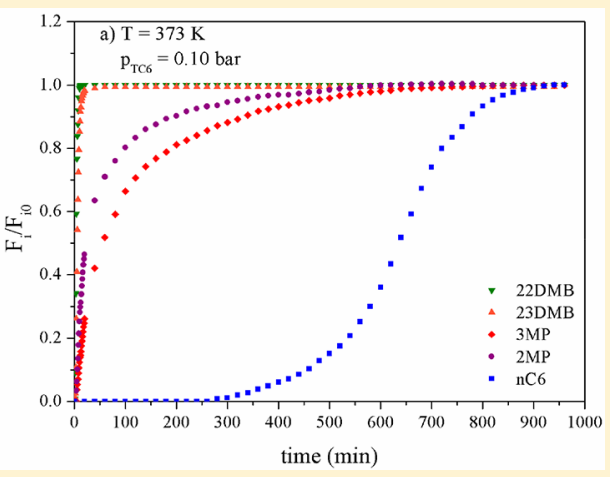
$22 \mathrm{DMB}$ is practically excluded from the framework followed closely by 23DMB. The adsorption equilibrium experimental data are modeled by the Sips isotherm and the breakthrough data are simulated through a mathematical model developed in Matlab code using the method of lines (MOL), the results being in qualitative agreement. From the numerical simulations it was found that diffusivity of the branched paraffins in ZIF-8 is 2 orders of magnitude lower than for the linear nC6, and that the diffusivity of the dibranched paraffins is three times lower than for the monobranched ones. This work shows that ZIF- 8 has the ability to purely separate the linear nC6 from its branched isomers and partially separate mono- from dibranched isomers if proper experimental conditions are setup, the result being important for the octane upgrade of gasoline.
\end{abstract}

\subsection{INTRODUCTION}

The separation of hydrocarbon mixtures has become one of the most important topics in the petrochemical industry, including the separation of paraffins isomers in the range $\mathrm{C5} /$ C6 for the octane upgrade of gasoline. Nowadays, the main technologies related to the hexane isomers separation by gas phase adsorption (physisorption) are the so-called Total Isomerization Process licensed by UOP LCC (Universal Oil Products $)^{1-3}$ and the Ipsorb and Hexorb Processes commercialized by Axens (a commercial branch of Institut Français du Pétrole, IFP). ${ }^{4-6}$ These processes employ zeolite 5A to kinetically separate low research octane number (RON) linear paraffins [e.g., $n$-hexane (nC6: RON 24)] from their respective branched isomers with higher RON content [e.g., 3methylpentane (3MP: RON 74.5), 2-methylpentane (2MP: RON 73.4), 2,3-dimethylbutane (23DMB: RON 101.7) and 2,2-dimethylbutane (22DMB: RON 91.8)]. Indeed, zeolite 5A shows an excellent molecular sieving effect, its pore aperture is satisfactorily large to adsorb linear paraffins and totally exclude branched isomers. Unfortunately, this material is not suitable to kinetically separate branched isomers, and the presence of monoparaffins such as $2 \mathrm{MP}$ and $3 \mathrm{MP}$ in the final product contribute to the decrease of performance of such processes.

To overcome this drawback, there is a vital need to search for alternative adsorbents able to separate the hexane isomers by classes according to the branching degree, dibranched (22 $\mathrm{DMB}$ and 23DMB) from monobranched (3MP and 2MP) and linear (nC6) paraffins. Traditionally, this is an area where zeolites are well-known and there are indications from patent and papers literature that the dibranched isomers can be separated from the others isomers using zeolites as adsorbents, with a wide variety of zeolites mentioned as candidates, such as SAPO-5, AlPO-5, SSZ-24, MCM-22, zeolite beta, among others. $^{7-13}$ However, compared to this, there are relatively few studies on applying metal organic frameworks (MOFs) that can efficiently separate the hexane isomers by classes according to the degree of branching, especially via kinetic mechanisms.

Received: October 16, 2018

Revised: December 4, 2018

Accepted: December 11, 2018

Published: December 11, 2018 


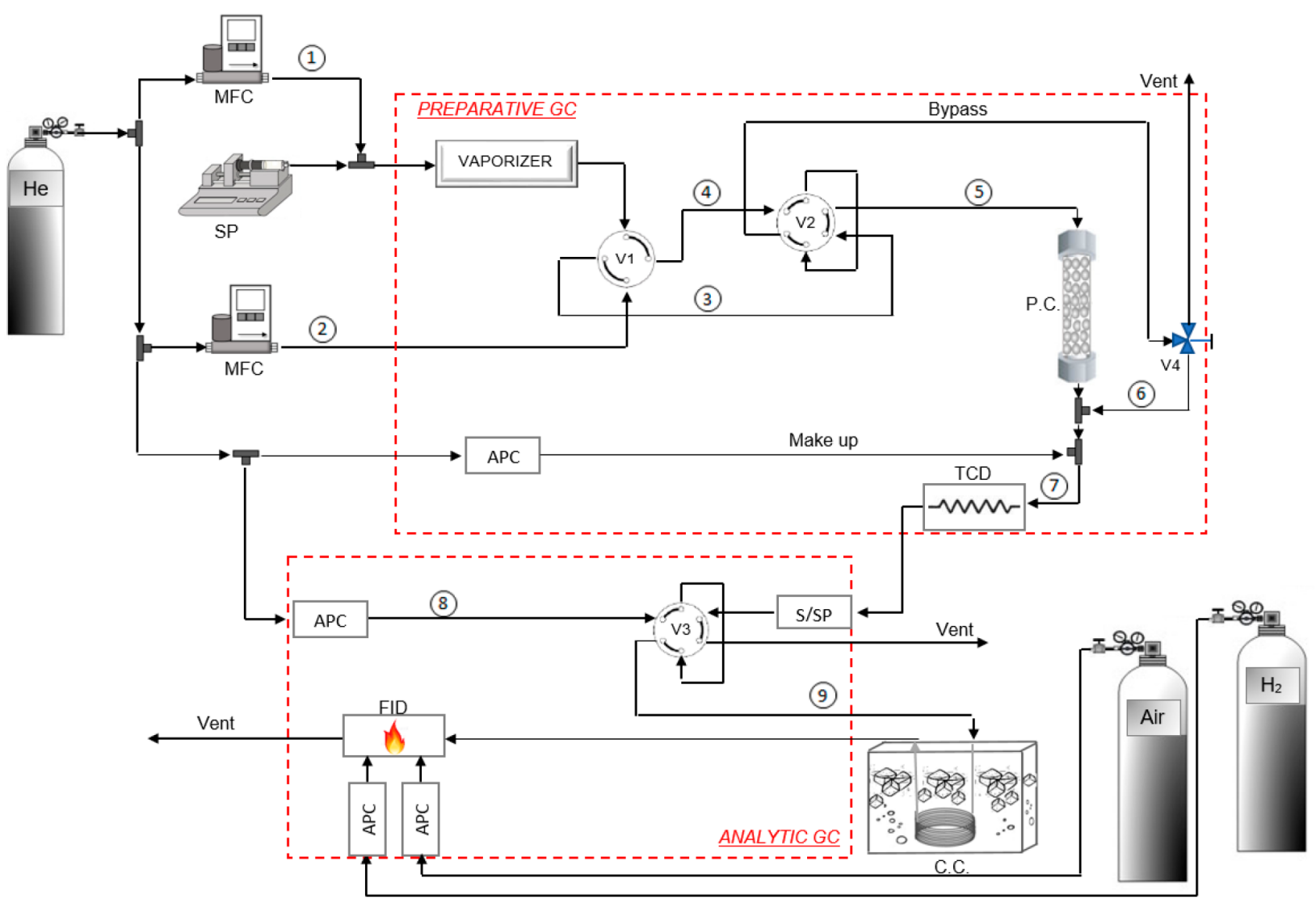

Figure 1. Schematic diagram of the experimental apparatus used to measure multicomponent breakthrough curves: (MFC) mass flow controller; (SP) syringe pump; (PC) packed column; (CC) capillary column; (APC) advanced pneumatic control; (S/SP) split/splitless-injector; (TCD) thermal conductivity detector; (FID) flame ionization detector; (V1) 4-way valve; (V2) and (V3) 6-way valve; (V4) 3-way valve; (11-(9) streams.

In this context, the newest class of crystalline porous material has been studied for this separation target. ${ }^{14-17}$ Owing to the chemical and thermal stability, zeolite imidazolate frameworks are of particular interest. ${ }^{18}$ This subfamily of metal organic frameworks are three-dimensional structures built up from metal centers connected by organic ligands based upon imidazolate ( Im) units. Particularly, the zinc methyl-imidazolate ZIF-8, has being applied in studies dealing with the kinetic separation of alkane isomers. This material has the formula $\mathrm{Zn}(\mathrm{MeIM})_{2}$, the $\mathrm{Zn}^{2+}$ cations being coordinated to four methyl-imidazolate ligands (MeIM) resulting in a material with the sodalite (SOD) topology (the same topology found in some zeolites). The structure formed comprises a cubic arrangement with eight sodalite cages at the corners, with a pore diameter of $11.4 \AA$, connected by flexible six-membered-rings pore windows with a free aperture of $3.4 \AA$. ZIF-8 possesses an important porosity, showing a surface area $\left(S_{\mathrm{BET}}\right)$ of $\sim 1810 \mathrm{~m}^{2} \cdot \mathrm{g}^{-1}$ and pore volume $\left(V_{\mathrm{p}}\right)$ of $\sim 0.66 \mathrm{~cm}^{3} \cdot \mathrm{g}^{-1} \cdot 18$

Some studies have addressed the ZIF-8 for hexane isomers separation. The first one was reported by Chang et al. ${ }^{19}$ in which it was shown that ZIF-8 coated capillary columns are highly capable of sieving branched from linear isomers. Peralta et al. ${ }^{20}$ performed screening tests by means of breakthrough experiments using binary mixtures. The linear paraffin nC6 was completely separated from its respective dibranched isomer $22 \mathrm{DMB}$, and a partial separation of the $3 \mathrm{MP}$ from the $22 \mathrm{DMB}$ isomer was also verified. Subsequently, Dubbeldam et al. ${ }^{21}$ and Herm et al. $^{22}$ evaluated the sorption behavior of ZIF- 8 by means of CBMC simulations and an interesting picture was observed. Dubbeldam et al. $^{21}$ reported a mixed sorption hierarchy while Herm et al., ${ }^{22}$ by introducing intracrystalline diffusional resistances, stated a normal sorption hierarchy. Thereafter, Ferreira et al. $^{23}$ studied the hexane isomers sorption under static conditions where only the dibranched isomer 22DMB was not adsorbed. Zhang et al. ${ }^{24}$ also studied the sorption of hexane isomers under static conditions and completely different results were obtained, being the dibranched isomer 23DMB most preferable adsorbed than its respective monobranched and linear isomers. Recently, Mendes et al. ${ }^{17}$ evaluated the performance of this material from competitive breakthrough experiments (binary and ternary systems), wherein no separation was detected in the binary system $(3 \mathrm{MP} / 22 \mathrm{DMB})$. Finally, Chen et al. ${ }^{25}$ studied the adsorption of $\mathrm{nC} 6$ and $2 \mathrm{MP}$ under static and dynamic conditions. In both conditions, the linear nC6 was much more adsorbed than $2 \mathrm{MP}$ isomer.

The above studies highlight the potential of ZIF- 8 for the hexane isomers separation and its prospective application in the petroleum industry. However, there is no complete understanding in the use of this material for this separation target. Indeed, some authors have completely different picture from others and none of those experimental works reported approached all five hexane isomers simultaneously. Thus, the goal of this work is to contribute to a better understanding of the adsorption of hexane isomers on ZIF- 8 through fixed bed adsorption experiments. For the first time, experimental breakthrough curves with an equimolar quinary mixture of 


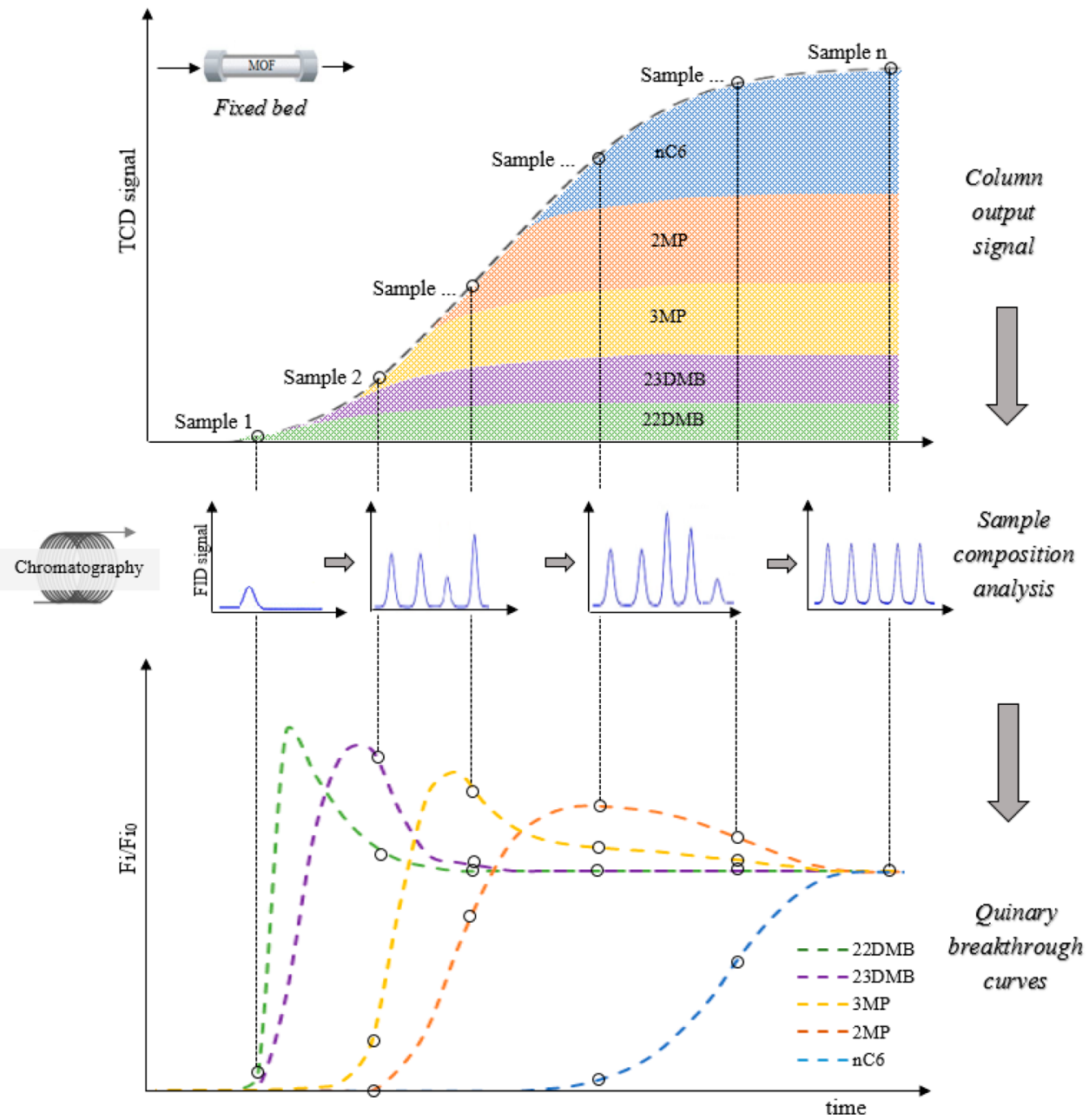

Figure 2. Schematic diagram of the experimental procedure used for multicomponent breakthrough curves measurements (e.g., mixture of all five isomers).

all five isomers (nC6, 3MP, $2 \mathrm{MP}, 23 \mathrm{DMB}$, and 22DMB) were measured. The influence of temperature and total hydrocarbon pressure were analyzed to evaluate the sorption dynamics behavior. Moreover, the data obtained were modeled by the Sips isotherm model, and thermodynamic parameters such as saturation loading, equilibrium affinity constants, and heats of sorption were determined. Finally, all calculated data were used to develop a mathematical model, in Matlab code through the method of lines (MOL), to predict the experimental breakthrough curves and validate the thermodynamic isotherm model.

\subsection{EXPERIMENTAL SECTION}

2.1. ZIF-8 and Hexane Isomers. The ZIF- 8 studied in this work was provided in shaped form by TU Dresden, Materials Center (details at http://www.metal-organicframeworks.eu/pdf/adsorbentien/zif8.pdf) with an average particle size of $2 \mathrm{~mm}$ (Figure S1, Supporting Information). The hexane isomers studied are 2,2-dimethybutane (22DMB), 2,3-dimethybutane (23DMB), 3-methylpentane (3MP), 2methylpentane (2MP), and $n$-hexane (nC6). These five isomers studied were of analytical grade supplied by SigmaAldrich.

2.2. Experimental Apparatus for Breakthrough Experiments. The performance of ZIF-8 in the separation of all five hexane isomers was achieved from breakthrough experiments in the vapor phase at an apparatus developed at LSRE-LCM (Polytechnic Institute of Bragança), for which Figure 1 shows its schematic diagram. The experimental system is mainly composed by two gas chromatographs (YL Instruments Co., Ltd.), one being preparative and the other being analytic. The apparatus consists of three main sections: (i) a gas preparation section, (ii) an adsorption section, (iii) an analytical section.

In the gas preparation section, the paraffins mixture and the carrier gas are introduced into the system. Helium is used as a carrier gas due its inertness and is introduced in the system in four different streams: the lines (1), (2), make up, and (8). The first three lines are directed to the preparative chromatograph while line (8) is sent to the analytical chromatograph. The lines (1) and (2) are monitored by mass flow controller (MFC) while the make up and line (8) pass through an advanced pneumatic controller (APC). The hydrocarbon mixture is continuously introduced (in liquid phase) in the preparative chromatograph by a syringe pump (SP) and is mixed with the carrier gas flowing in the line (1) to run through the vaporizer.

The adsorption column (stainless steel with a $0.01 \mathrm{~m}$ internal diameter and $0.12 \mathrm{~m}$ length) is entirely filled with the adsorbent material and operated inside the preparative chromatograph oven. In the measurement of multicomponent breakthrough curves, the stream coming from the vaporizer 


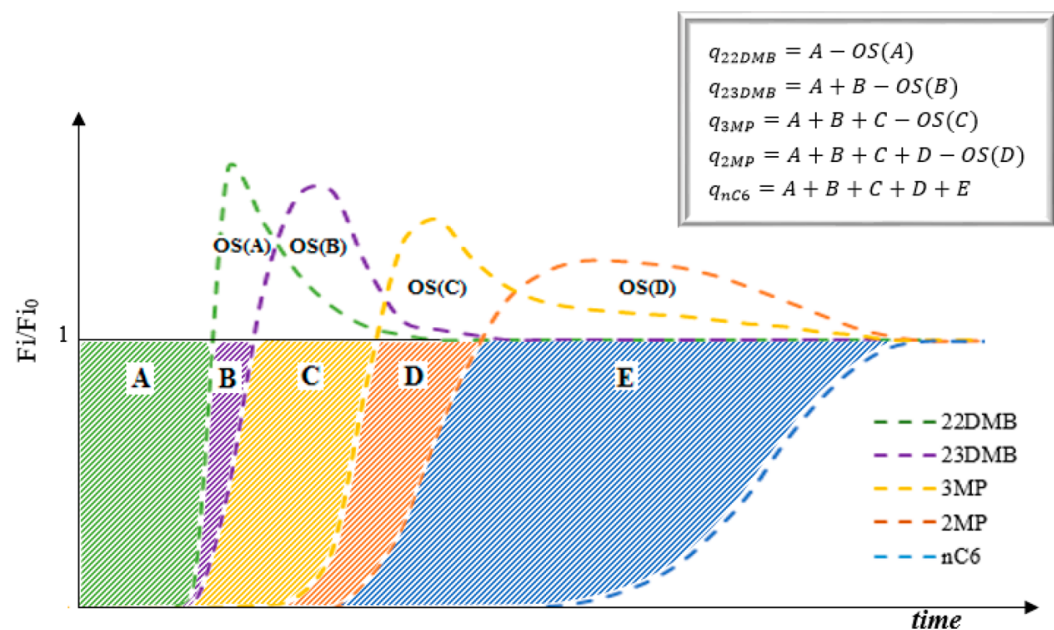

Figure 3. Schematic diagram showing the method used to calculate the loadings from breakthrough curves (e.g., mixture of all five isomers).

passes through the valves (V1 and V2) and goes directly into the adsorption column via line (5), whereas the pure helium from line (2) is directed to a vent via a bypass line. At the same time, the output of the packed bed is diluted by the helium flowing through the make up line and directed to a thermal conductivity detector (TCD) where is constantly monitored. From the preparative to analytic chromatograph the transfer line is thermally controlled to kept the temperature stability and avoid any condensation of the gases.

In the last section, analytical, the effluent flowing in the transfer line goes to the analytic chromatograph, passing through a split/splitless (S/SP) injector and then is directed to a VICI Valco 6-way sampling valve (V3). In a predefined time interval, this valve send a $250 \mu \mathrm{L}$ aliquot of gas to a capillary GC column (Supelco with a $15 \mathrm{~m}$ length, $0.1 \mathrm{~mm}$ outside diameter and $0.1 \mu \mathrm{m}$ poly(dimethyl sulfoxane) coating) coating, via line (9) by the pure helium stream coming from line (8). The chromatographic column is immersed in an ice water bath for better separation of hexane isomers peaks. ${ }^{22}$ Finally, the capillary GC column output goes to the flame ionization detector (FID) to be analyzed. The concentration signals from TCD and FID are continuously recorded on a personal computer.

When the experiment finishes, for example, the saturation state is reached, the paraffins injection by the syringe pump is cut and the valve (V1) is actuated, allowing the carrier gas to flow through line (2) cleaning the adsorption column. Thereafter, another experiment can be performed. It is important to take into account, that before start any experience, the bypass line can be used to check if the paraffins vaporization is stable, for example, if it shows a constant concentration in the TCD. For that, the vaporized mixture should be directly sent to the TCD via line (6). When the concentration reaches a constant signal, the experiment can be started.

2.3. Experimental Procedure for Breakthrough Measurements. The experimental procedure to measure multicomponent breakthrough curves has been illustrated in Figure 2. The concentration profile of hexane isomers is continuously measured as a function of time at the outlet of the bed. For that, the packed bed is saturated by introducing, at the inlet, the feed containing the paraffins mixture with a known composition and molar flux in a helium stream at a constant total hydrocarbon pressure and temperature. During the saturation stage, samples from the column outlet are collected, every minute, to be chromatographically evaluated.

The equilibrium loading of each component in the mixture is obtained by integrating the measured breakthrough curves. A schematic example of the procedure used for a quinary mixture of hexane isomers is shown in Figure 3. In graphical terms, the amount adsorbed for the first isomer to elute from the column, in this example $22 \mathrm{DMB}$, is equal to area $A$ minus the roll-up area $\operatorname{OS}(A)$ (overshoot). For the second isomer, 23DMB, the amount adsorbed is equal to area $A$ plus area $B$ minus roll-up $\mathrm{OS}(B)$ and so on for the others isomers.

The adsorbed amount, $q_{\exp , i}$, at equilibrium conditions for each isomer in the porous material is calculated accordingly to the following eq:

$$
q_{\text {exp }, i}=\frac{1}{m_{\mathrm{ads}}}\left(F_{i 0} t_{n}-\int_{0}^{t_{\infty}} F_{i} \mathrm{~d} t-\varepsilon_{\mathrm{b}} V_{\mathrm{c}} C_{i 0}\right)
$$

where $m_{\mathrm{ads}}$ is the adsorbent mass in the column, $F_{0, i}$ is the feed molar flow rate of hexane isomers, $F_{i}$ is the molar flow rate of hexane isomers in the bulk gas phase, $t_{\infty}$ is the saturation bed time, $\varepsilon_{\mathrm{b}}$ is the bed porosity, $V_{\mathrm{c}}$ is the column adsorption volume, and $C_{0, i}$ is the feed gas phase concentration at the inlet of the fixed bed. The term $\varepsilon_{\mathrm{b}} V_{\mathrm{c}} C_{i} 0 / m_{\mathrm{ads}}$ represents the adsorbed amount of sorbate gas in the column void space.

\subsection{THEORY}

3.1. Sips Model Isotherm. The model used to interpret the equilibrium adsorption behavior data in ZIF-8 was the Sips isotherm, also known as Langmuir-Freundlich (LF) equation. $^{26,27}$ This thermodynamic model was proposed by Robert Sips and describes both Langmuir ${ }^{28}$ and Freundlich ${ }^{29}$ adsorption behaviors. The isotherm for multicomponent systems is given by the following equation:

$$
q_{\text {Sips }, i}=q_{\max i} \frac{\left(b_{i} p_{i}\right)^{1 / n_{i}}}{1+\sum_{k=1}^{j}\left(b_{k} p_{k}\right)^{1 / n_{k}}}
$$

where $q_{S \text { ips } i}$ is the loading, $q_{\text {maxi }}$ is the maximum saturation loading, $b_{i}$ is the adsorption equilibrium affinity constant, $p$ is the partial pressure, and $n_{i}$ is the heterogeneity index. When $n$ is equal to 1 the material has a homogeneous surface and the model reduces to Langmuir isotherm applicable for ideal 
Table 1. Dynamic Mathematical Model Equations for Fixed Bed Adsorption in ZIF-8

fixed bed adsorption

mass balance to sorbate species

overall mass balance

mass transfer rate

energy balance: gas phase

energy balance: solid phase

isotherm model equations

$$
\begin{aligned}
& \varepsilon_{\mathrm{b}} D_{\mathrm{axi}} \frac{\partial}{\partial z}\left(C_{t} \frac{\partial y_{i}}{\partial z}\right)=\frac{\partial}{\partial z}\left(F y_{i}\right)+\varepsilon_{\mathrm{b}} \frac{\partial}{\partial t}\left(C_{t} y_{\mathrm{i}}\right)+\left(1-\varepsilon_{\mathrm{b}}\right) \rho_{\mathrm{a}} \sum_{i=1}^{n_{\mathrm{cp}}} \frac{\partial \bar{q}_{i}}{\partial t} \\
& \frac{\partial F}{\partial z}+\varepsilon_{\mathrm{b}} \frac{\partial C_{t}}{\partial t}+\left(1-\varepsilon_{\mathrm{b}}\right) \rho_{\mathrm{a}} \sum_{i=1}^{n_{\mathrm{cp}}} \frac{\partial \bar{q}_{i}}{\partial t}=0 \\
& \frac{\partial \bar{q}_{i}}{\partial t}=k_{\mathrm{LDF}}\left(q^{*}-\bar{q}_{i}\right) \\
& K_{\mathrm{ax}} \frac{\partial^{2} T}{\partial z^{2}}=F c_{\mathrm{pg}} \frac{\partial T}{\partial z}+\varepsilon_{\mathrm{b}} C_{\mathrm{t}} c_{\mathrm{pg}} \frac{\partial T}{\partial t}+\left(1-\varepsilon_{\mathrm{b}}\right) a_{\mathrm{p}} h_{f}\left(T-T_{\mathrm{s}}\right)+a_{\mathrm{c}} h_{\mathrm{w}}\left(T-T_{\mathrm{w}}\right) \\
& \rho_{\mathrm{a}} c_{p s} \frac{\partial T_{\mathrm{s}}}{\partial t}=a_{\mathrm{p}} h_{\mathrm{p}}\left(T-T_{\mathrm{s}}\right)+\rho_{\mathrm{a}} \sum_{i=1}^{n_{\mathrm{cp}}}\left(-\Delta H_{i}\right) \frac{\partial \bar{q}_{i}}{\partial t} \\
& q_{i}=q_{\max i} \frac{(11)}{\left.1+\sum_{i} p_{i}\right)^{1 / n_{i}}}\left(b_{k} p_{k}\right)^{1 / n_{k}}
\end{aligned}
$$

\begin{tabular}{|c|c|c|c|c|c|c|c|c|c|c|c|}
\hline \multirow[b]{2}{*}{ run } & \multirow[b]{2}{*}{$\begin{array}{c}\text { temp } \\
(\mathrm{K})\end{array}$} & \multirow[b]{2}{*}{$\begin{array}{l}\text { helium flow rate } \\
\left(\mathrm{mL} \cdot \mathrm{min}^{-1}\right)\end{array}$} & \multirow[b]{2}{*}{$\begin{array}{l}\text { total } \mathrm{C}_{6} \text { flow rate } \\
\left(\mu \mathrm{mol} \cdot \mathrm{min}^{-1}\right)\end{array}$} & \multirow[b]{2}{*}{$\begin{array}{c}\text { total } \mathrm{C}_{6} \\
\text { pressure (bar) }\end{array}$} & \multirow{2}{*}{$\begin{array}{c}\text { mass of } \\
\text { adsorbent } \\
(\mathrm{kg})\end{array}$} & \multicolumn{5}{|c|}{ loading $\left(\mathrm{mol} \cdot \mathrm{kg}^{-1}\right)$} & \multirow[b]{2}{*}{$\begin{array}{l}\text { total loading } \\
\left(\mathrm{mol} \cdot \mathrm{kg}^{-1}\right)\end{array}$} \\
\hline & & & & & & $22 \mathrm{DMB}$ & 23DMB & $3 \mathrm{MP}$ & $2 \mathrm{MP}$ & nC6 & \\
\hline $1-1$ & 373 & 3.31 & 16.20 & 0.10 & $1.8 \times 10^{-03}$ & 0.006 & 0.020 & 0.123 & 0.210 & 1.127 & 1.487 \\
\hline $1-2$ & & 2.76 & 40.51 & 0.25 & & 0.011 & 0.034 & 0.163 & 0.270 & 1.388 & 1.866 \\
\hline $1-3$ & & 1.84 & 81.01 & 0.50 & & 0.017 & 0.044 & 0.196 & 0.315 & 1.580 & 2.152 \\
\hline $2-1$ & 423 & 3.31 & 16.20 & 0.10 & $1.8 \times 10^{-03}$ & 0.004 & 0.014 & 0.059 & 0.098 & 0.298 & 0.472 \\
\hline $2-2$ & & 2.76 & 40.51 & 0.25 & & 0.009 & 0.027 & 0.111 & 0.186 & 0.640 & 0.973 \\
\hline $2-3$ & & 1.84 & 81.01 & 0.50 & & 0.015 & 0.038 & 0.148 & 0.254 & 0.864 & 1.319 \\
\hline $3-1$ & 473 & 3.31 & 16.20 & 0.10 & $1.8 \times 10^{-03}$ & 0.003 & 0.009 & 0.029 & 0.050 & 0.086 & 0.177 \\
\hline $3-2$ & & 2.76 & 40.51 & 0.25 & & 0.007 & 0.017 & 0.058 & 0.103 & 0.193 & 0.379 \\
\hline $3-3$ & & 1.84 & 81.01 & 0.50 & & 0.013 & 0.032 & 0.104 & 0.174 & 0.357 & 0.681 \\
\hline
\end{tabular}

Table 2. Experimental Conditions for Equimolar Quinary Breakthrough Curves of Hexane Isomers in ZIF-8 and Loadings

surfaces. The index $j$ refers to the number of components present in the mixture.

The temperature dependence in the heterogeneity parameter $n_{i}^{30}$ and in the adsorption affinity constant $b_{i}^{30}$ are taking into account according to the following equations, respectively:

$$
\begin{aligned}
& \frac{1}{n_{i}}=\frac{1}{n_{i, 0}}+\alpha_{i}\left(1-\frac{T_{0}}{T}\right) \\
& b_{i}=b_{\infty, i} \mathrm{e}^{\left(-\Delta H_{i} /(R T)\right)}
\end{aligned}
$$

where $n_{i, 0}$ is the heterogeneity index at the reference temperature, $T_{0}, b_{i, \infty}$ is the frequency factor of the affinity constant at the infinite temperature, $\Delta H_{i}$ is the heat of sorption, $R$ is the universal gas constant, $T$ is the temperature, and $\alpha$ is a constant parameter.

The isosteric heat $\left(-Q_{i}\right)$ for the temperature dependence of the Sips equation can be calculated in terms of amount adsorbed according to the following equation, ${ }^{30}$ considering that the parameter $q_{\max i}$ is invariant with temperature:

$$
\left(-Q_{i}\right)=\Delta H_{i}-\left(\alpha R T_{0}\right) n_{i}^{2} \ln \left(\frac{q_{\text {Sips }, i}}{q_{\text {maxi }}-q_{\text {Sips }, i}}\right)
$$

The multicomponent isotherms were modeled using a numerical procedure in order to minimize the mean relative deviations $(\bar{\Delta} q)$ given by the function: ${ }^{31}$

$$
\bar{\Delta} q=\frac{1}{N} \sum_{i=1}^{N} \sqrt{\left(\frac{q_{\text {exp }, i}-q_{\text {Sips }, i}}{q_{\text {exp }, i}}\right)^{2}}
$$

where $N$ is the total number of the experiments.

3.2. Numerical Modeling of Multicomponent Breakthrough Experiments. The formulation of a mathematical model, to simulate the adsorption dynamics behavior of a multicomponent mixture of hexane isomers (nC6, 2MP, 3MP, $23 \mathrm{DMB}$, and 22DMB) flowing through a fixed bed containing the microporous adsorbent ZIF-8, involves a set of partial differential equations (PDEs). This system is constituted by the mass and energy conservation laws, a general isotherm to describe the adsorption behavior, and a control mechanism for the kinetic mass transfer from the bulk gas phase to the adsorbent. According to these assumptions the model equations are presented in Table 1 . In the Supporting Information S2 a detailed description of the model is given.

3.3. Numerical Solution of Model Equations. The system of coupled partial differential equations was reduced first to a set of ordinary differential equations (ODEs) applying the method of lines (MOL) in Matlab code. The method of lines is a semidiscrete method, discretizing only the spatial derivatives while the time variable is kept continuous. Detailed information on MOL can be found in Schiesser. ${ }^{32}$ The spatial (boundary-value) partial derivatives were approximated algebraically by finite differences using the dss routines, a 
library of differentiation routines in Matlab, including approximations from second order to 10th order. The resultant system was integrated using the stiff integrator, ode15s. The dss routines can be found in the Schiessers web page. ${ }^{33}$

\subsection{RESULTS AND DISCUSSION}

4.1. A Series of Breakthrough Experiments. The adsorption behavior of all five hexane isomers nC6, 2MP, $3 \mathrm{MP}, 23 \mathrm{DMB}$, and $22 \mathrm{DMB}$ in ZIF-8 was investigated through multicomponent breakthrough experiments with equimolar mixtures. The experiments were performed at the temperatures 373,423 , and $473 \mathrm{~K}$, total hydrocarbon pressure, $p_{T C 6}$ of 0.10 , 0.25 , and 0.50 bar and using helium to setup a total pressure in the column of 1 bar. Complete information on the experimental conditions are detailed in Table 2, including the amount adsorbed of the isomers and total amount adsorbed in the runs. The experiments were conducted in order to ensure a residence time in the bed, $\tau_{f b}=L / v$ (where $L$ is the column length and $v$ is the interstitial velocity), of approximately $45 \mathrm{~s}$.

From Table 2 one can see that the mixture loadings are thermodynamically consistent, since they increase as the total hydrocarbon pressure increases (at a constant temperature) and decrease as the temperature increases (at a constant total hydrocarbon pressure). The experimental data clearly show that a significant amount of the $\mathrm{nC} 6$ can be adsorbed in ZIF-8 with values at $373 \mathrm{~K}$ and at a total hydrocarbon pressure of 0.5 bar reaching $1.58 \mathrm{~mol} \cdot \mathrm{kg}^{-1}$. However, with increasing temperature this value decreases to $0.357 \mathrm{~mol} \cdot \mathrm{kg}^{-1}$ at the temperature of $473 \mathrm{~K}$

Figures 4, 5, and 6 show the breakthrough curves for the temperatures 373,423 , and $473 \mathrm{~K}$, respectively, plotted in terms of normalized molar flow rate $F / F_{i 0}$ as a function of time. In each figure the effect of total hydrocarbon pressure is shown: (a) 0.10, (b) 0.25, and (c) 0.50 bar.

As a whole, the results shown in these figures indicate that the sorption hierarchy of hexane isomers in ZIF-8 is always $\mathrm{nC} 6>2 \mathrm{MP}>3 \mathrm{MP}>23 \mathrm{DMB}>22 \mathrm{DMB}$ (normal hierarchy), being similar to the order of the normal boiling point of the compounds. However, the profile of the breakthrough curve of nC6 is very different from the one observed for the branched paraffins, eluting at a stoichiometric time, $t_{\mathrm{st}}$ different from the residence time of the gas in the column, which means that the sorption of $\mathrm{nC6}$ is essentially dominated by equilibrium. In contrast, the branched isomers elute practically at the residence time of the gas in the column due to strong diffusional limitations. But the approach to feed concentration of the branched isomers is different, since the dibranched isomers $22 \mathrm{DMB}$ and 23DMB rapidly approach the inlet concentration at the early stage of the experiments, in contrast with the monobranched isomers $3 \mathrm{MP}$ and $2 \mathrm{MP}$ that due to less diffusion limitations produce a less sharp approach to inlet concentration. The retention time of the hexane isomers for all breakthrough runs (calculated from a material balance over the column) are reported in Table S3 of Supporting Information S3.

Practically, it can be concluded from all the experiments that 22DMB is completely excluded from the framework of ZIF-8. The 23DMB shows a similar behavior, with very small quantities adsorbed, where the highest loading obtained at $373 \mathrm{~K}$ and $0.5 p_{\text {TC } 6}$ is equal to $0.044 \mathrm{~mol} \cdot \mathrm{kg}^{-1}$. These observations show that ZIF-8 completely separates the linear nC6 from its isomers and partially separates the branched
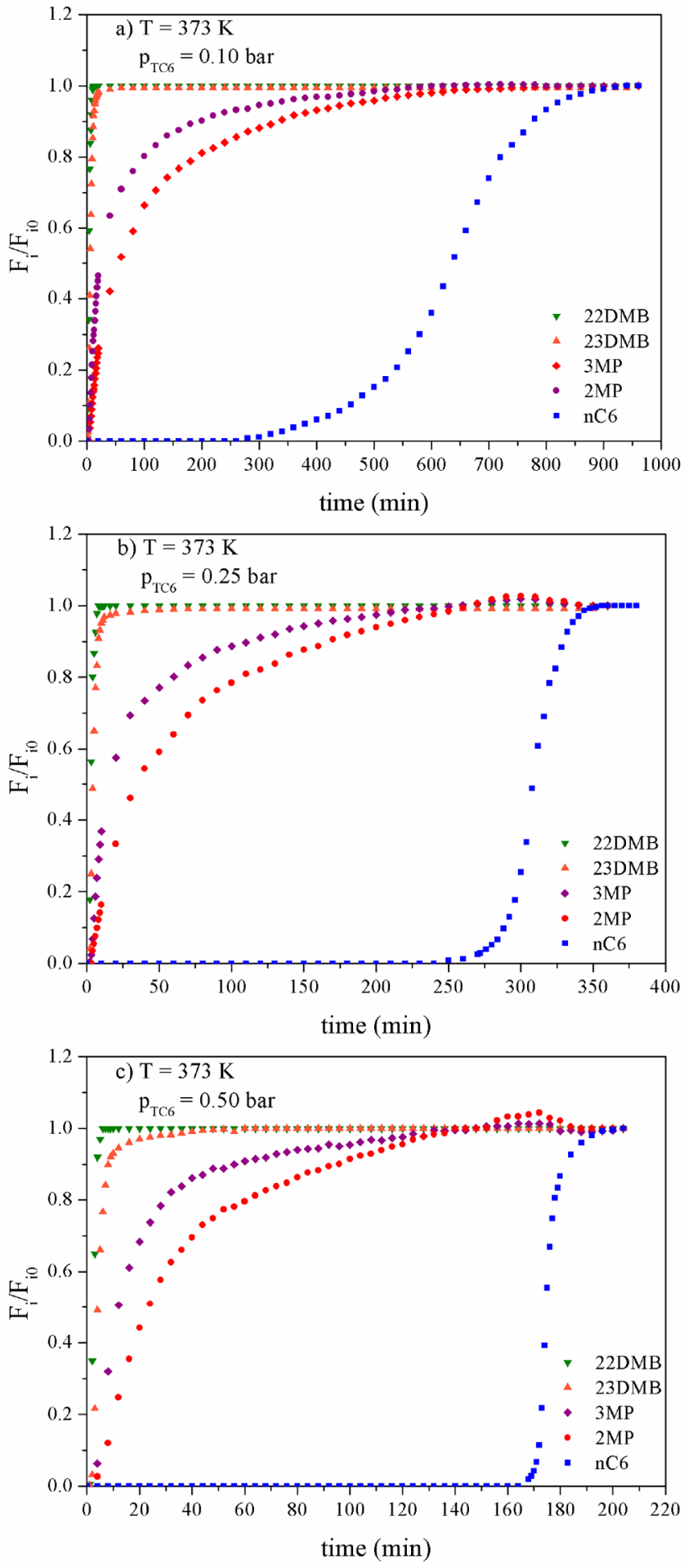

Figure 4. Experimental quinary breakthrough curves for an equimolar mixture of hexane isomers in ZIF-8 at $373 \mathrm{~K}$ and $p_{\mathrm{TC} 6}$ : (a) $0.10 \mathrm{bar}$, (b) 0.25 bar, and (c) 0.50 bar.

isomers (via a kinetic mechanism) which is an important result for petrochemical applications viewing the octane improvement of gasoline, such as the total isomerization process.

The ability of ZIF-8 to partially separate monobranched/ dibranched hexane isomers has already been observed by Peralta et al. ${ }^{20}$ for a binary mixture $3 \mathrm{MP} / 22 \mathrm{DMB}$, but here we can observe clearly the separation into three classes of hexane isomers: linear (nC6)/monobranched $(2 \mathrm{MP}, 3 \mathrm{MP}) / \mathrm{di}$ - 

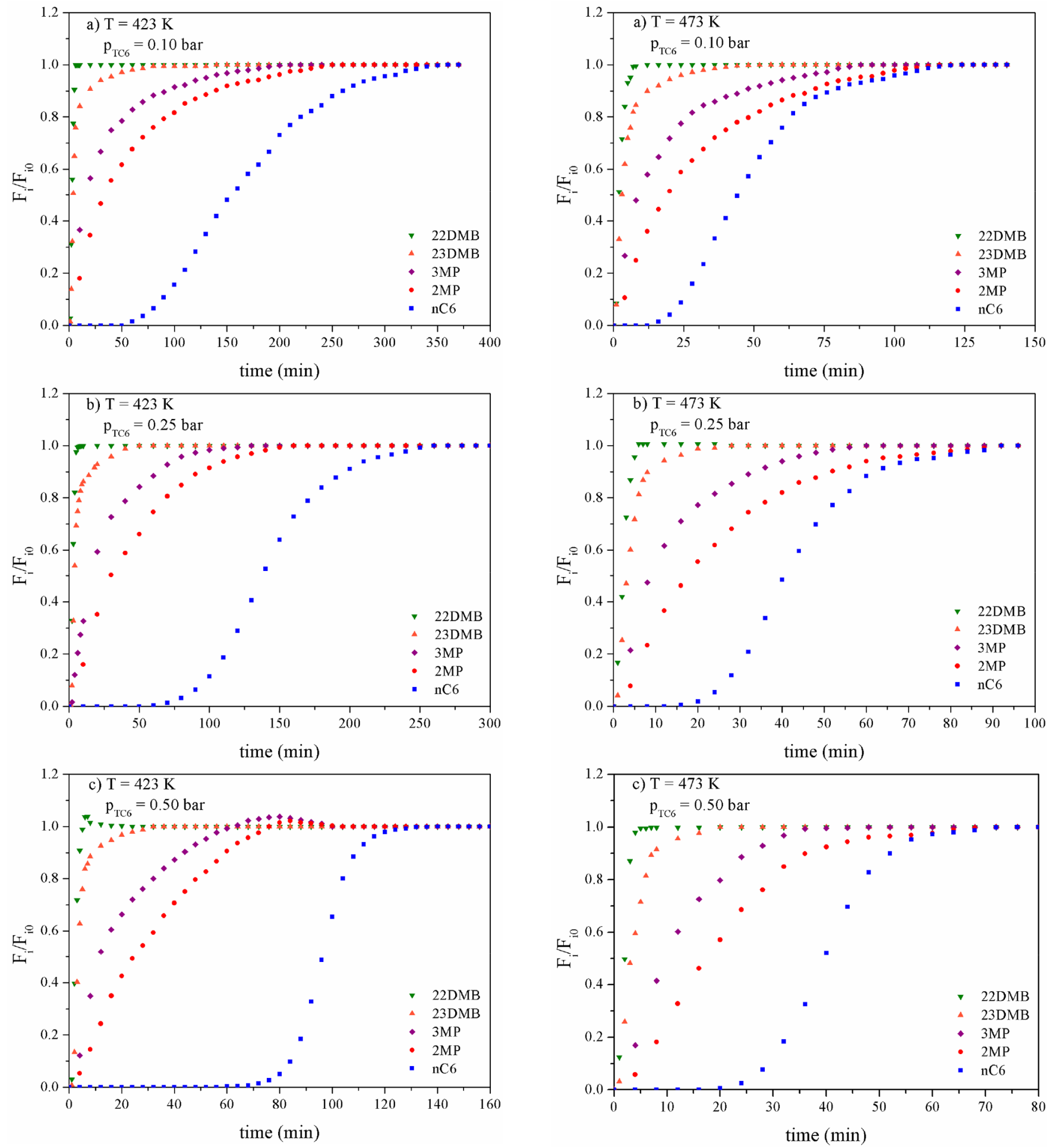

Figure 5. Experimental quinary breakthrough curves for an equimolar mixture of hexane isomers in ZIF-8 at $423 \mathrm{~K}$ and $p_{\mathrm{TC} 6}$ : (a) $0.10 \mathrm{bar}$, (b) 0.25 bar, and (c) 0.50 bar.

branched (23DMB, 22DMB). However, the fraction of dibranched isomers will always be contaminated with the monobranched ones, even in small quantities, since they both start eluting at the residence time of the gas in the bed. Moreover, the sorption hierarchy nC6 $\gg 2 \mathrm{MP}>3 \mathrm{MP} \gg$ $23 \mathrm{DMB}>22 \mathrm{DMB}$ is for the first time reported, and its slightly different from the one predicted by Herm et al. ${ }^{22}$ from equilibrium CBMC simulations, where considering equal

Figure 6. Experimental quinary breakthrough curves for an equimolar mixture of hexane isomers in ZIF-8 at $473 \mathrm{~K}$ and $p_{\text {TC6 }}$ : (a) $0.10 \mathrm{bar}$, (b) 0.25 bar, and (c) 0.50 bar.

diffusivities for $2 \mathrm{MP}$ and $3 \mathrm{MP}$, breakthrough simulations ${ }^{22}$ predict that $2 \mathrm{MP}$ start to elute previously than $3 \mathrm{MP}$. Another important issue that leads to the observations sketched in Figures 4, 5, and 6 is the space time (residence time) of the gas in the column, since in a previous work (Mendes et al. ${ }^{17}$ ) it has been shown that in experiments with a short space time of the gas in the column (around $2 \mathrm{~s}$ ) the only possible separation in ZIF-8 is for the linear/branched isomers, with no separation 

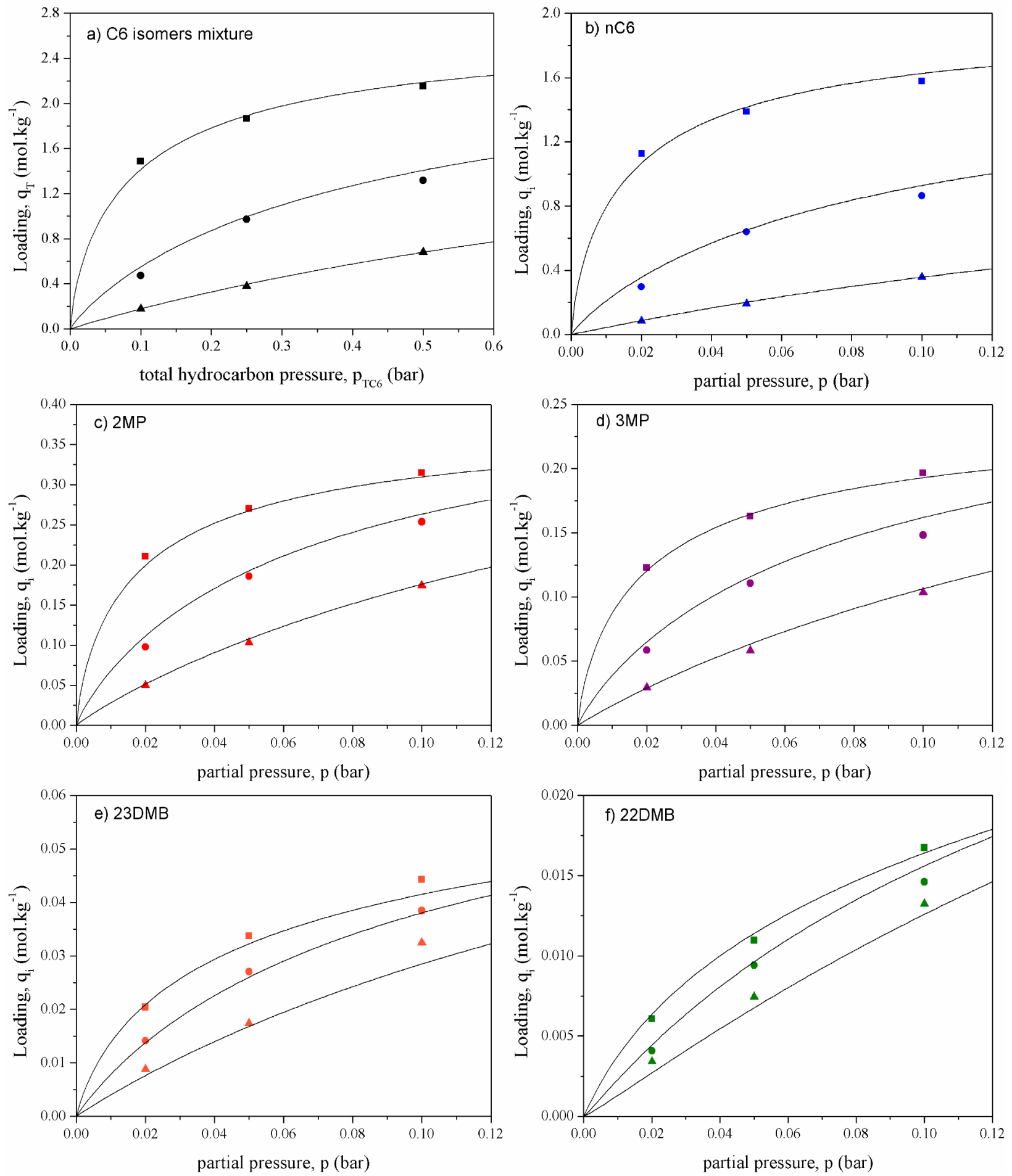

Figure 7. Adsorption equilibrium isotherms of hexane isomers in ZIF-8. Points are experimental data and the continuous lines represent the Sips

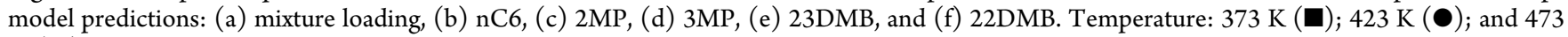
$\mathrm{K}(\boldsymbol{\Delta})$.

between monobranched/dibranched isomers. This is due to the very low diffusion of the branched isomers in ZIF-8 (especially $22 \mathrm{DMB}$ and $23 \mathrm{DMB}$ ) that can be exploited to separate them, if a suitable residence time of the gas in the column is setup. In the experiments reported in this work, the residence time of the gas in the column is $45 \mathrm{~s}$, which combined with the diffusional time constants $\left(D_{c} / r_{c}{ }^{2}\right)$ of the paraffins, results in a significant degree of separation between monobranched (2MP/3MP) and dibranched isomers (22DMB/23DMB). This is an important characteristic of ZIF-8 that could be exploited for the separation of hexane isomers.

Regarding the effect of partial pressure on breakthrough curves at each temperature, it is visible on Figures 4, 5, and 6 the favorable nature of the adsorption equilibrium of nC6 with increasing partial pressure (panels $a, b$, and $c$ on both figures). 


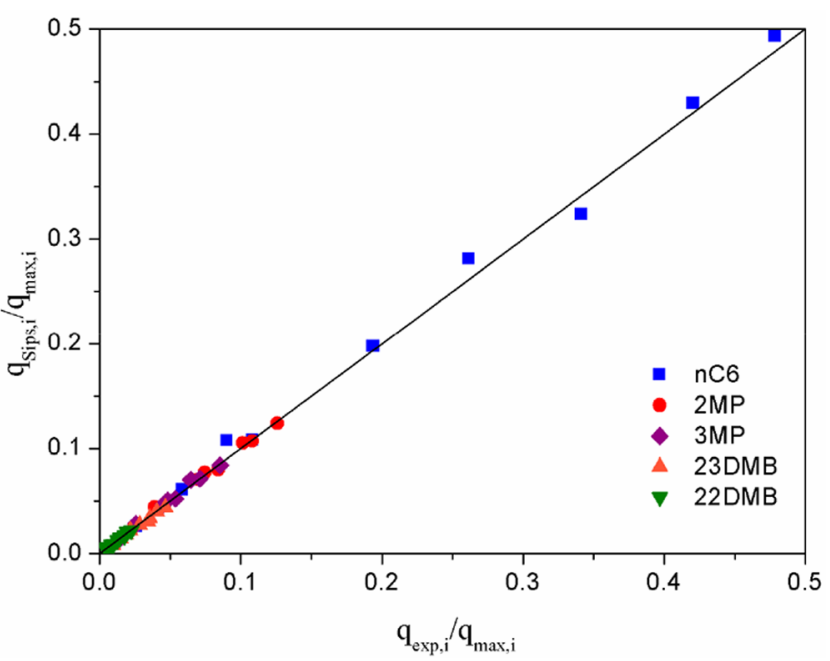

Figure 8. Parity plot comparing the experimental data and model predictions in terms of fractional loading.

Table 3. Sips Parameters and Deviation between Model and Experimental Data

\begin{tabular}{|c|c|c|c|c|c|}
\hline \multirow[b]{2}{*}{ Sips parameters } & \multicolumn{5}{|c|}{ hexane isomers } \\
\hline & nC6 & $2 \mathrm{MP}$ & $3 \mathrm{MP}$ & $23 \mathrm{DMB}$ & $22 \mathrm{DMB}$ \\
\hline$q_{\max , i}\left(\mathrm{~mol} \cdot \mathrm{kg}^{-1}\right)$ & 3.30 & 2.50 & 2.30 & 0.95 & 0.75 \\
\hline$-\Delta H_{i}\left(\mathrm{~kJ} \cdot \mathrm{mol}^{-1}\right)$ & 41.65 & 25.23 & 22.99 & 21.04 & 17.77 \\
\hline$n_{i, 0}{ }^{a}$ & 1.33 & 1.31 & 1.28 & 1.09 & 0.93 \\
\hline $\begin{array}{l}\alpha_{i} \\
T=373 \mathrm{~K}\end{array}$ & 1.34 & 0.72 & 0.83 & 0.25 & 0.13 \\
\hline$n_{i, 1}$ & 1.33 & 1.31 & 1.28 & 1.09 & 0.93 \\
\hline $\begin{array}{l}b_{i}\left(\mathrm{bar}^{-1}\right) \\
T=423 \mathrm{~K}\end{array}$ & 27 & 4.32 & 2.70 & 1.60 & 1.11 \\
\hline$n_{i, 2}$ & 1.10 & 1.18 & 1.14 & 1.06 & 0.91 \\
\hline $\begin{array}{l}b_{i}\left(\mathrm{bar}^{-1}\right) \\
T=473 \mathrm{~K}\end{array}$ & 5.53 & 1.66 & 1.12 & 0.72 & 0.56 \\
\hline$n_{i, 3}$ & 0.97 & 1.09 & 1.04 & 1.03 & 0.90 \\
\hline $\begin{array}{l}b_{i}\left(\mathrm{bar}^{-1}\right) \\
\bar{\Delta} q\end{array}$ & 1.58 & 0.78 & $\begin{array}{l}0.56 \\
0.010\end{array}$ & 0.38 & 0.33 \\
\hline
\end{tabular}

${ }^{a}$ The reference temperature used was $T_{0}=373 \mathrm{~K}$.

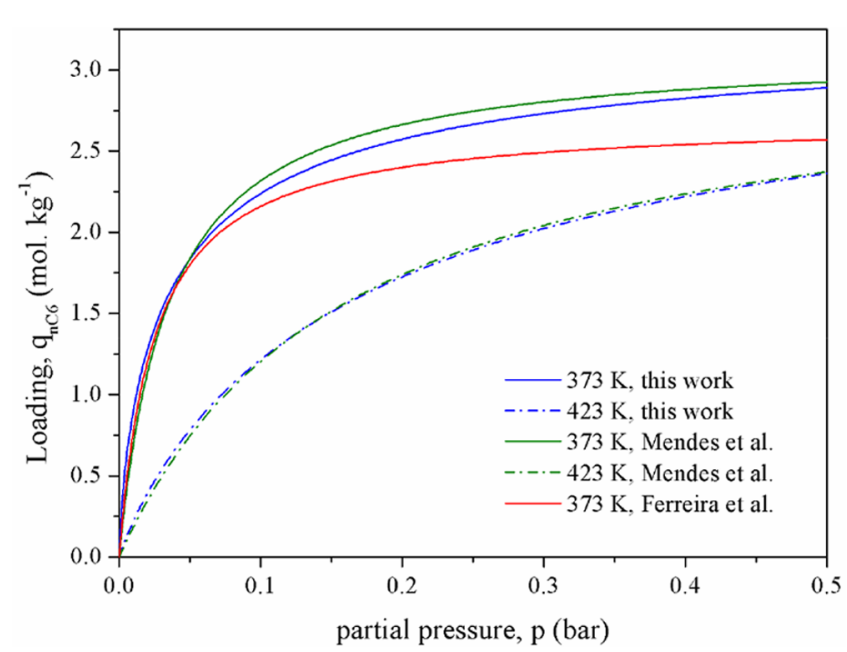

Figure 9. Single component isotherms of nC6 in ZIF-8. Literature comparison between model predictions.
As the partial pressure of nC6 increases, the wavefront of $n \mathrm{C} 6$ becomes more sharp. For the monobranched isomers $2 \mathrm{MP}$ and $3 \mathrm{MP}$ it is also shown in Figure $4 \mathrm{~b}, \mathrm{c}$ for the total hydrocarbon pressure of 0.25 and 0.50 bar, respectively, an increasing competition for sorption with nC6, with an observed roll-up in concentration near the time of elution of the nC6 concentration wavefront.

The effect of temperature on the concentration profiles of the hexane isomers observed in the breakthrough curves is also very significant. At the higher temperature of $473 \mathrm{~K}$ (Figure 6) the elution time of $\mathrm{nC} 6$ is significantly reduced being closer to the one of the monobranched isomers $2 \mathrm{MP}$ and $3 \mathrm{MP}$, where nC6 reach the inlet concentration (saturate) practically at the same time as the monobranched compounds. This is due to the decreasing selectivity with increasing temperature between the linear nC6 and monobranched 2MP and 3MP. It can be also noted, that the dibranched isomers (22DMB and 23DMB) continue to be practically excluded from the framework.

4.2. Modeling Multicomponent Adsorption Isotherms. For the development of an adsorption process, the modeling of the adsorption equilibrium data is very important. However, in this work (flow system) the measurement of equilibrium data from the breakthrough curves (eq 1), should be made with caution, since the sorption of $\mathrm{nC} 6$ is equilibrium based in contrast with the sorption of the branched isomers which is kinetically controlled. In kinetically controlled systems the measurement of equilibrium data from breakthrough curves (flow system) can give rise to very high discrepancies relatively to data collected in a static system (Mendes et al. ${ }^{17}$ ). Thus, the modeled isotherms for the branched isomers presented in this section may not represent the true adsorption equilibrium in ZIF-8 as measured in a static system, and can have only application for the present system studied. However, it is possible to ensure that for a flow system with a residence time of the gas around $45 \mathrm{~s}$ with similar sized particles of ZIF8 , the data can be assumed as true, since several adsorption/ desorption cycles were performed and results obtained were the same, meaning that there is no mass accumulation inside the particles.

This consideration (the correct setup of the residence time of the gas in the column) should be taken into account regarding the design of cyclic processes to separate hexane isomers into fractions. This also explains the discrepancies between the data reported by several authors in the literature for this system. ${ }^{17,20-25}$ Accordingly, the equilibrium data reported here for $22 \mathrm{DMB}, 23 \mathrm{DMB}, 3 \mathrm{MP}$, and $2 \mathrm{MP}$ may be considered as pseudoequilibrium data. Moreover, if the stoichiometric time changes in the fixed bed (in these experiments is $45 \mathrm{~s}$ ) and also the adsorbent particles size (in these experiments is around $2 \mathrm{~mm}$ ) the thermodynamic data calculated and used to simulate the overall data may also change.

Figure 7 shows the adsorption isotherms measured from the multicomponent experiments and the fitting with the Sips model (pronounced as type I in IUPAC classification), where a good agreement between model and experimental data can be seen. The experimental values were obtained by applying eq 1 to the breakthrough curves. Besides, the parity plot (Figure 8), with the fractional loading of model predictions plotted against the fractional loading of experimental data, confirms this good agreement. 

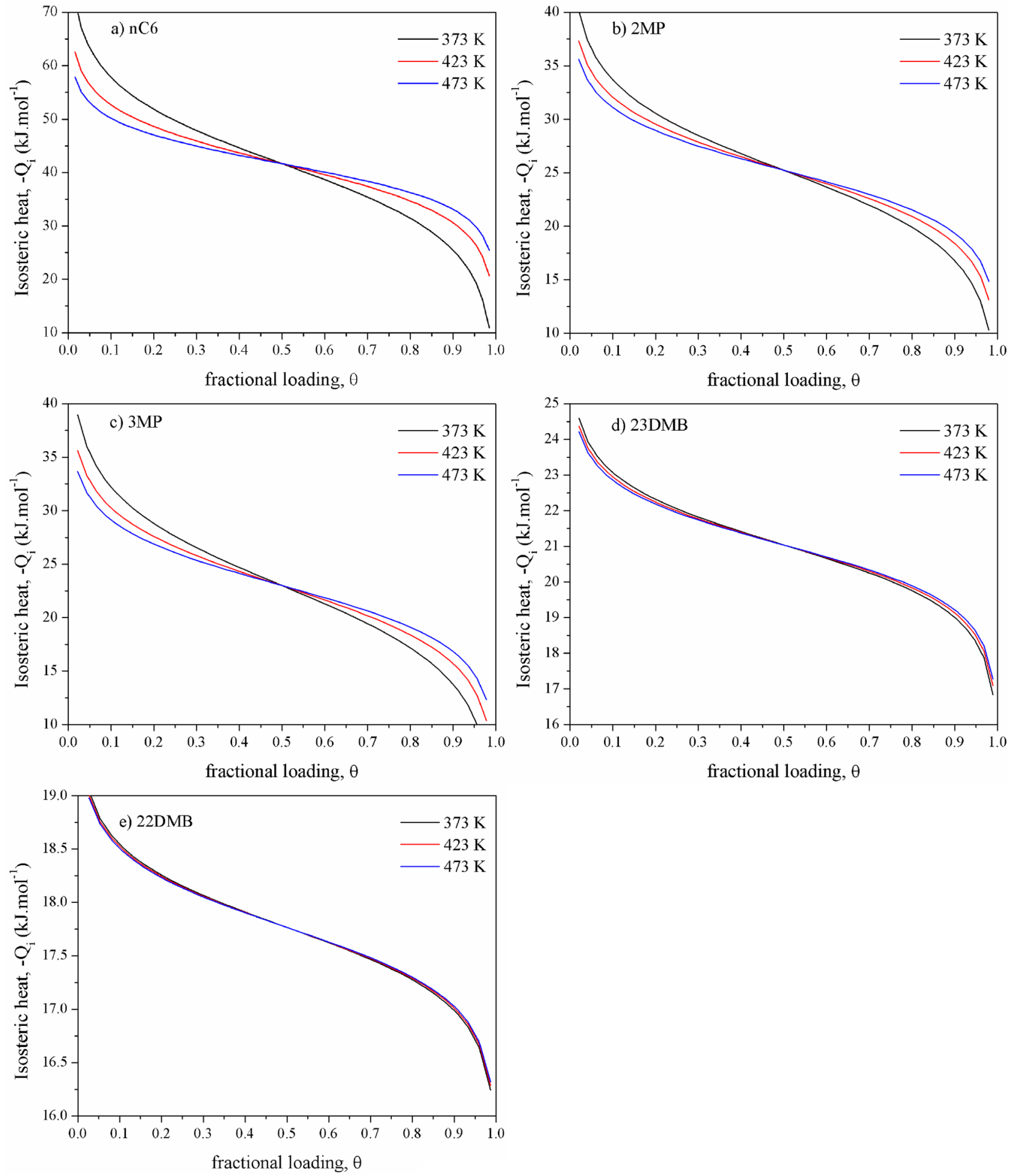

Figure 10. Isosteric heat of hexane isomers in ZIF-8: (a) nC6, (b) 2MP, (c) 3MP, (d) 23DMB, and (e) 22DMB.

The fitted parameters and the average deviation between model and experimental data are given in Table 3. For all components, the saturation loading, adsorption affinity constant, and the heats of sorption (magnitude) follow the normal sorption hierarchy order observed in the breakthrough curves: $\mathrm{nC} 6>2 \mathrm{MP}>3 \mathrm{MP}>23 \mathrm{DMB}>22 \mathrm{DMB}$. One should specify that at $373 \mathrm{~K}$ the adsorption affinity constant for the linear $\mathrm{nC6}$ is more than 20 times higher than for the dibranched ones, decreasing significantly at the temperature to
$473 \mathrm{~K}$. Table 3 also specifies the heterogeneity parameter $n$, the value of which decreases with temperature, indicating that the heterogeneity of the system is smaller as the temperature increases.

For the nC6 (since its sorption behavior is equilibrium based, data can be compared with that in the literature), the saturation loading is equal to $3.3 \mathrm{~mol} \cdot \mathrm{kg}^{-1}$, being its value very close to the one found by Mendes et al. ${ }^{17}\left(3.1 \mathrm{~mol} \cdot \mathrm{kg}^{-1}\right)$ and slightly higher than the one found by Ferreira et al. ${ }^{23}(2.7 \mathrm{~mol}$. 


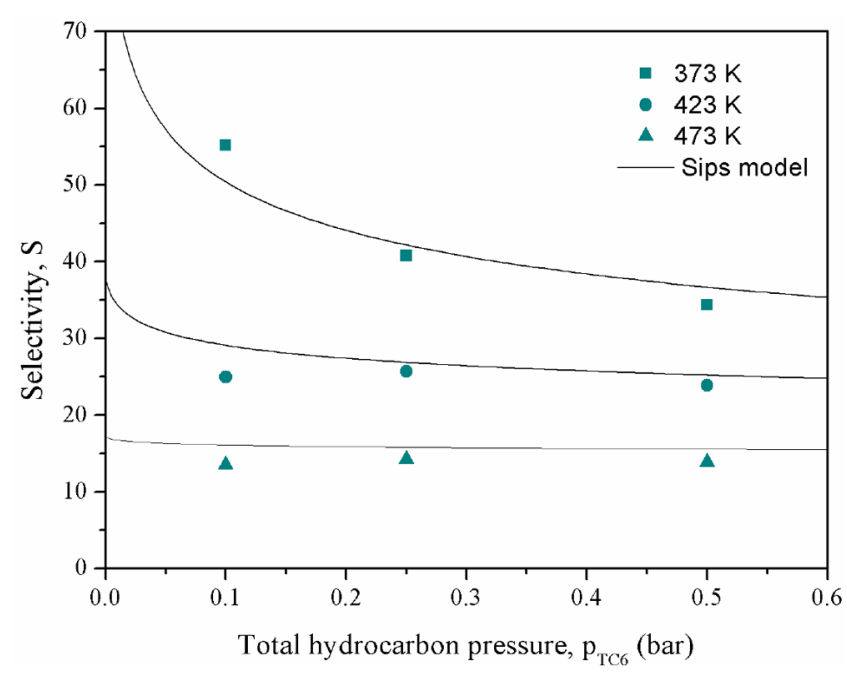

Figure 11. Sorption selectivity as a function of total hydrocarbon pressure, $p_{\mathrm{TC} 6}$.

$\mathrm{kg}^{-1}$ ). Additionally, the $\mathrm{nC} 6$ affinity constant lies between 27 $\mathrm{bar}^{-1}(373 \mathrm{~K})$ to $1.58 \mathrm{bar}^{-1}(473 \mathrm{~K})$, the value being obtained at $373 \mathrm{~K}$ similar to the one reported by Mendes et al. ${ }^{17}$ (28.4 $\mathrm{bar}^{-1}$ ) and lower than the one reported by Ferreira et al. ${ }^{23}$ (40 $\mathrm{bar}^{-1}$ ). Regarding the heat of sorption, the value is around 41.6 $\mathrm{kJ} \cdot \mathrm{mol}^{-1}$ reflecting the strong impact of the temperature on the adsorption of nC6. This value was also observed by Ferreira et $\mathrm{al}^{23}\left(41.4 \mathrm{~kJ} \cdot \mathrm{mol}^{-1}\right)$ and is higher than the one calculated by Mendes et al. ${ }^{17}\left(32.8 \mathrm{~kJ} \cdot \mathrm{mol}^{-1}\right)$. We should note here that both authors Mendes et al. and Ferreira et al. ${ }^{23}$ fitted their experimental data with the Langmuir isotherm model.

Figure 9 shows the single components isotherms for the nC6 predicted by Sips model (this work) and Langmuir model (Mendes et al. ${ }^{17}$ and Ferreira et al. ${ }^{23}$ ) in similar conditions. As can be seen the isotherms predicted by the Sips model are very similar to those reported by Mendes et al., ${ }^{17}$ for both temperatures 373 and $473 \mathrm{~K}$, being slightly lower at the temperature of $373 \mathrm{~K}$. Comparing the results of this work with the ones reported by Ferreira et al., ${ }^{23}$ at lower partial pressures, up to 0.1 bar all isotherms are in close agreement.

The isosteric heat was calculated from eq 5 an plotted for all isomers in Figure 10 as a function of the fractional loading, $\theta=$ $q_{i} / q_{\text {max }, i}$. Figure 10 shows that the isosteric heat decreases as the pressure increases, that is, with loading. In addition, in Figure 10 we can observe that the isosteric heat is also a function of temperature, reflecting the dependence of the parameters $b$ and $n$.

To evaluate the adsorption performance of ZIF- 8 to obtain high RON mixtures, the selectivities were calculated and plotted as a function of the total hydrocarbon pressure. For an equimolar mixture, a convenient definition can be $\mathrm{e}^{21}$

$$
S_{\mathrm{ads}}=\frac{q_{\mathrm{nC} 6}+q_{2 \mathrm{MP}}+q_{3 \mathrm{MP}}}{q_{23 \mathrm{DMB}}+q_{22 \mathrm{DMB}}}
$$

Figure 11 discloses the sorption selectivity as a function of total hydrocarbon pressure, where it can be observed that the selectivity decreases with increasing temperature. A remarkable value of approximately 55 is found at $373 \mathrm{~K}$ and $p_{\mathrm{TC} 6}$ of 0.10 bar. The selectivity decreases with increasing total hydrocarbon pressure, being close to 35 at 0.50 bar. At 423 and $473 \mathrm{~K}$ the total hydrocarbon pressure has almost no effect on selectivity.
Another remark is that lower temperatures increase the selectivity, mainly because nC6 sorption increases significantly at lower temperatures. One can also note that the selectivities predicted by the Sips model, represented by the lines in Figure 11 are in good agreement with the experimental ones.

4.3. Numerical Modeling of Multicomponent Breakthrough Curves. The development of a mathematical model for the study of sorption dynamics in a fixed bed is a very important task for the design of cyclic industrial processes. Thus, all experimental multicomponent breakthrough curves, previously showed in section 4.1, were fitted with the fixed bed adsorption model described in section 3.2.

The breakthrough simulations were performed in two ways (two panels, 1 and 2): (i) panel 1 accounting for strong intracrystalline diffusional resistances (low diffusivities) for the branched isomers (Figures 12, 13, 14 (a1), (b1), and (c1)) and (ii) panel 2 with weak diffusional resistances and equal for all the isomers (high diffusivities) (Figures 12, 13, 14 (a2), (b2), and (c2)). The differences between the diffusional resistances of the isomers in panel (1) is accounted by different ratios $\left(D_{\mathrm{nC} 6} / D_{2 \mathrm{MP}}\right),\left(D_{\mathrm{nC} 6} / D_{3 \mathrm{MP}}\right),\left(D_{\mathrm{nC} 6} / D_{23 \mathrm{DMB}}\right)$ and $\left(D_{\mathrm{nC} 6} /\right.$ $\left.D_{22 \mathrm{DMB}}\right)$, the ratios being equal to 1 in panel (2). All the model parameters used in the breakthrough simulations are summarized in Table S4 of the Supporting Information. As a starting point for the simulations shown in panels 1 , the ratio of diffusional resistances selected, were the ones reported by Herm et al. ${ }^{22}$ and calculated from CBMC predictions regarding the sorption of hexane isomers in ZIF-8 at $433 \mathrm{~K}$, where the predicted diffusivity ratios were for $D_{\mathrm{nC} 6} / D_{2 \mathrm{MP}}=$ $D_{\mathrm{nC} 6} / D_{3 \mathrm{MP}}=100$ and for $D_{\mathrm{nC} 6} / D_{23 \mathrm{DMB}}=D_{\mathrm{nC} 6} / D_{22 \mathrm{DMB}}=300$. These ratios ensure no diffusion limitations for nC6. Figures 12,13 , and 14 show the simulations results obtained at 373 , 423 , and $473 \mathrm{~K}$, respectively.

The best intracrystalline diffusivities ratios found in order to obtain the best fit of the experimental data are summarized in Table 4 and compared with those reported by Herm et al. ${ }^{22}$ Table 4 indicates that in the present experimental study, the diffusivity time constant of linear nC6 is approximately twice lower than the one estimated by CBMC. For the branched isomers, the diffusivity ratios $D_{\mathrm{nC} 6} / D_{2 \mathrm{MP}}$ and $D_{\mathrm{nC} 6} / D_{3 \mathrm{MP}}$ are equal to the ones predicted by CBMC, while that for the $D_{\mathrm{nC} 6} /$ $D_{23 \mathrm{DMB}}$ is twice lower than that for the $D_{\mathrm{nC} 6} / D_{22 \mathrm{DMB}}$ ratio. This means that the diffusivity of the branched paraffins in ZIF-8 is 2 orders of magnitude lower than that for the linear $\mathrm{nC} 6$, and that the diffusivity of the dibranched paraffins is three times lower than that for the monobranched ones. Therefore, the values obtained in this work validate in a certain way the CBMC results. The temperature dependence of the diffusivities was calculated giving rise to an activation energy for diffusion $\left(-E_{D i}\right)$ for all hexane isomers around $20 \mathrm{~kJ} \cdot \mathrm{mol}^{-1}$.

Figures 12-14 (panels a1, b1, and c1) show that the mathematical model is reasonably good to predict the concentration profiles of the breakthrough curves of the hexane isomers using a linear driving force model for mass transfer. It should be noted that it was only possible to qualitatively represent the experimental data by introducing strong intracrystalline diffusivities for the branched isomers according to the values reported in Table 4. However, although the model can capture the profile of the breakthrough curves, for some simulations the perfect match was not achieved, especially at the low temperatures. For example, the overshoots predicted by the model for branched isomers are higher than those obtained experimentally. Probably a more refined 

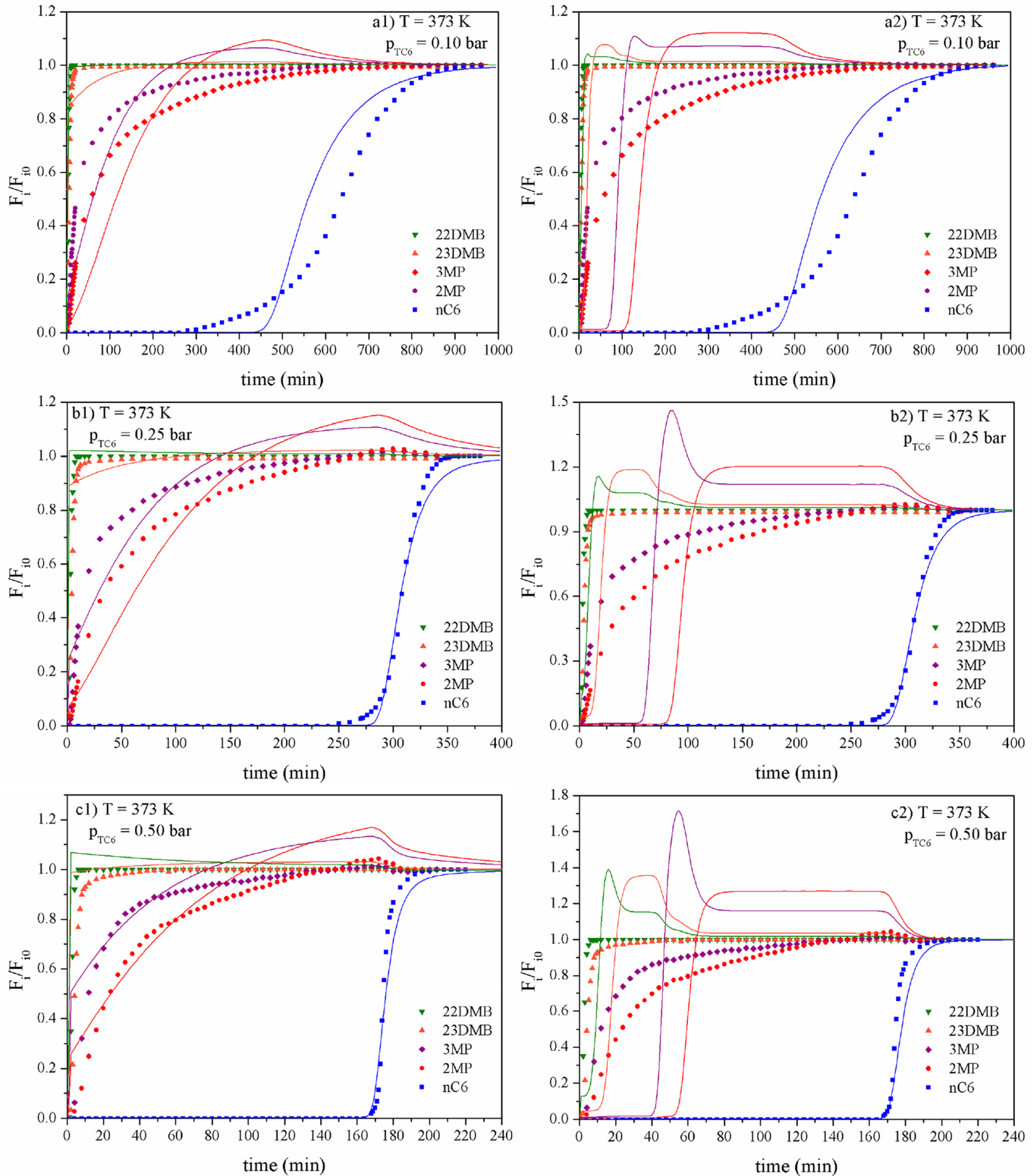

Figure 12. Experimental and numerical breakthrough curves for an equimolar mixture of hexane isomers in ZIF- 8 at $373 \mathrm{~K}$ and $\mathrm{p}_{\mathrm{TC}}$ : (a) 0.10 bar, (b) 0.25 bar, and (c) 0.50 bar. The continuous lines represent numerical predictions. Panels a1, b1, and c1 account for strong intracrystalline diffusion for branched isomers $\left(D_{\mathrm{nC} 6} / D_{2 \mathrm{MP}}=D_{\mathrm{nC} 6} / D_{3 \mathrm{MP}}=100, D_{\mathrm{nC} 6} / D_{23 \mathrm{DMB}}=150\right.$, and $\left.D_{\mathrm{nC} 6} / D_{22 \mathrm{DMB}}=300\right)$, and a2, b2, and c2 assume equal diffusivities.

diffusion model is necessary to account for the mechanism of mass transfer of the branched isomers in the ZIF-8 framework. However, in a general view the LDF and equilibrium model are reasonable to describe in a comprehensive manner the sorption phenomena of hexane isomers in ZIF-8 being a valuable tool to design cyclic adsorption processes for the separation of hexane isomers.
Figures 12-14 (panels a2, b2, and c2) show the simulations for which it was assumed equal diffusivities for all the isomers (with the same value of nC6 used in panels a1, b1, and c1). It is clear a completely different scenario, which proves that the sorption of branched paraffins in ZIF-8 is strongly diffusionally limited in contrast with the sorption of nC6 which can be assumed to be equilibrium based. 

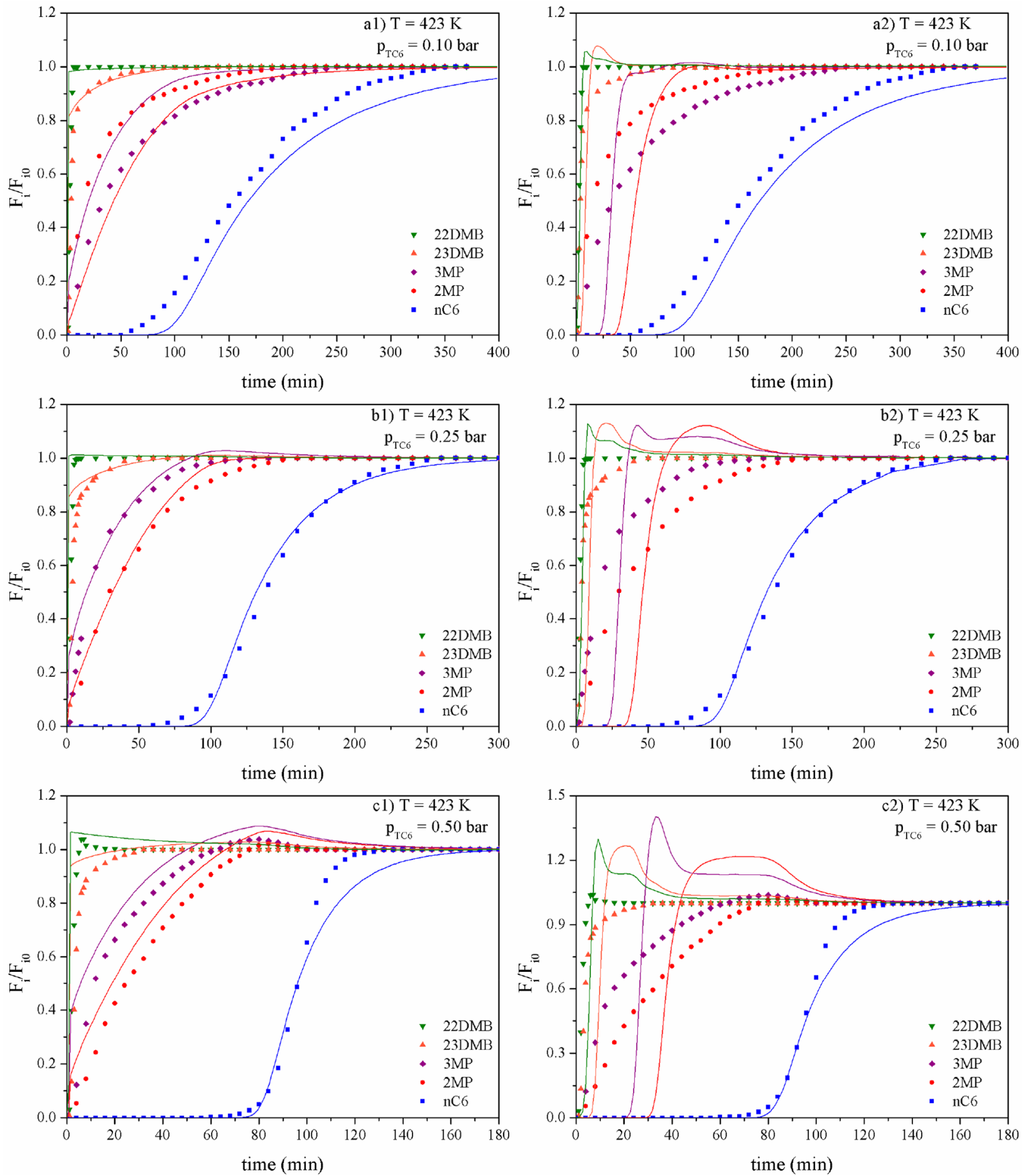

Figure 13. Experimental and numerical breakthrough curves for an equimolar mixture of hexane isomers in ZIF- 8 at $423 \mathrm{~K}$ and $p_{\text {TC6 }}$ : (a) 0.10 bar, (b) 0.25 bar, and (c) 0.50 bar. The continuous lines represent numerical predictions. Panels a1, b1, and c1 account for strong intracrystalline diffusion for branched isomers $\left(D_{\mathrm{nC} 6} / D_{2 \mathrm{MP}}=D_{\mathrm{nC} 6} / D_{3 \mathrm{MP}}=100, D_{\mathrm{nC} 6} / D_{23 \mathrm{DMB}}=150\right.$, and $\left.D_{\mathrm{nC} 6} / D_{22 \mathrm{DMB}}=300\right)$, and a2, b2, and c2 assume equal diffusivities.

As a final remark, the data reported in this work prove that it is possible to separate linear/monobranched/dibranched hexane isomers in ZIF-8 taking into account the strong and different diffusional resistances of the branched isomers.

\section{CONCLUSIONS}

We present here the first experimental work dealing with the sorption of all five hexane isomers nC6/2MP/3MP/23DMB/
22DMB on the porous methylimidazolate MOF ZIF-8. A series of multicomponent (equimolar) breakthrough curves were measured analyzing the effect of temperature and partial pressure on the hexane isomers sorption. All experiments showed a normal sorption hierarchy nC6 > 2MP > $3 \mathrm{MP}>$ $23 \mathrm{DMB}>22 \mathrm{DMB}$, which is similar to the order of the normal boiling point of the compounds. In addition, the breakthrough curves show that linear nC6 can be completely separated from 

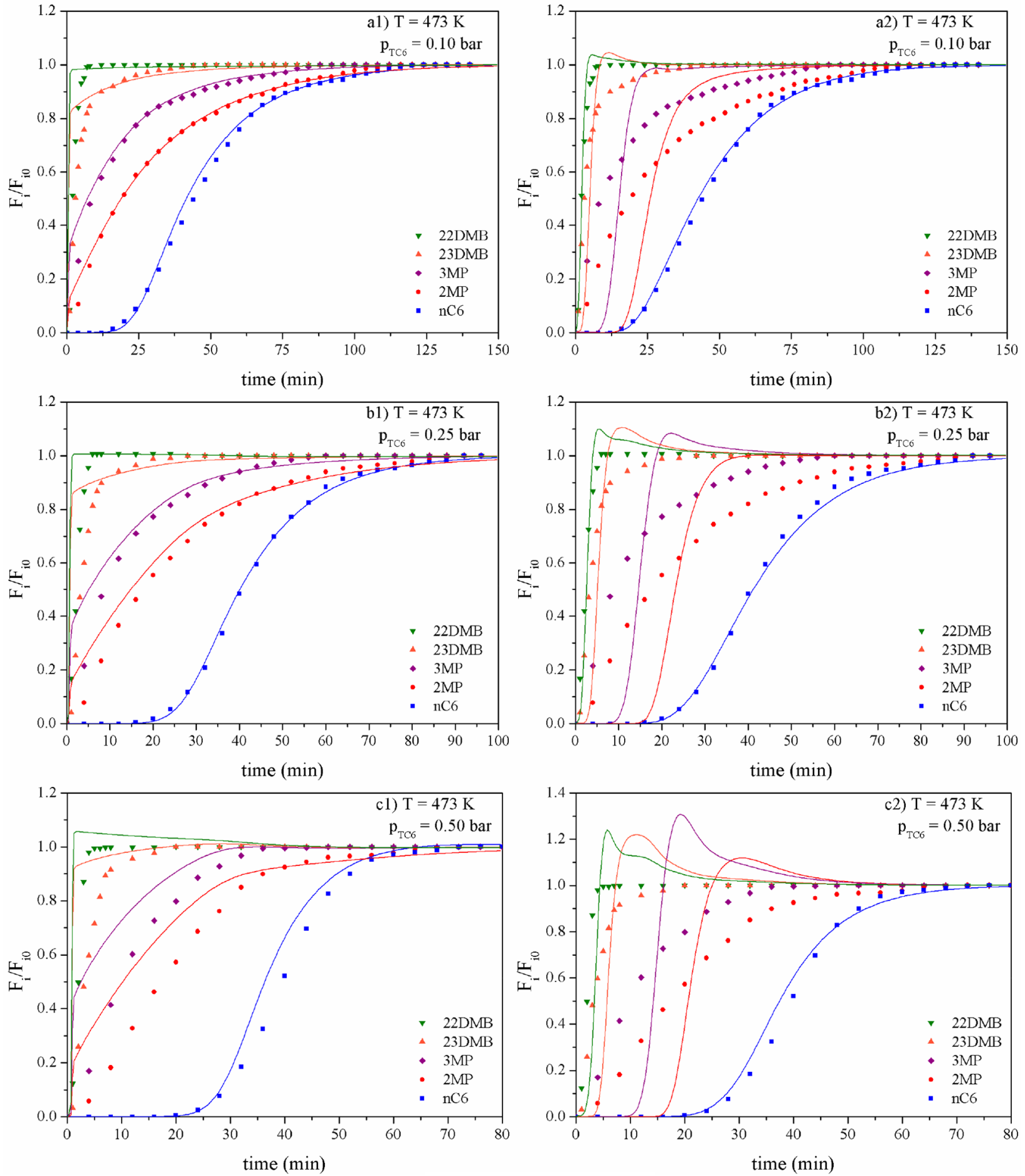

Figure 14. Experimental and numerical breakthrough curves for an equimolar mixture of hexane isomers in ZIF-8 at $473 \mathrm{~K}$ and $p_{\text {TC6 }}$ : (a) 0.10 bar, (b) 0.25 bar, and (c) 0.50 bar. The continuous lines represent numerical predictions. Panels a1, b1, and c1 account for strong intracrystalline diffusion for branched isomers $\left(D_{\mathrm{nC} 6} / D_{2 \mathrm{MP}}=D_{\mathrm{nC} 6} / D_{3 \mathrm{MP}}=100, D_{\mathrm{nC} 6} / D_{23 \mathrm{DMB}}=150\right.$ and $\left.D_{\mathrm{nC} 6} / D_{22 \mathrm{DMB}}=300\right)$, and a2, b2, and c2 assume equal diffusivities.

its alkanes isomers and a partial separation of branched isomers is achieved (specially at $373 \mathrm{~K}$ ). Since the monobranched $2 \mathrm{MP}$ and $3 \mathrm{MP}$ also start eluting at the beginning of experiments, it will not be feasible to obtain a fraction with purity dibranched alkanes; contamination with monobranched ones will always occur, even in small quantities.

A significant amount of these isomers can be adsorbed in ZIF-8 at $373 \mathrm{~K}$, where at a total hydrocarbon pressure of 0.5 bar, the loading value is $2.15 \mathrm{~mol} \cdot \mathrm{kg}^{-1}$. However, when the temperature decreases to $473 \mathrm{~K}$ the loading decreases to 0.68 $\mathrm{mol} \cdot \mathrm{kg}^{-1}$. The best selectivity is found at $373 \mathrm{~K}$ with a remarkable value around 55 at 0.10 bar of total hydrocarbon pressure, while at $473 \mathrm{~K}$ this value decreases to approximately 10.

Experimental data were fitted with the Sips model and a fixed bed adsorption mathematical model was developed in 
Table 4. Ratio of Diffusivities of Hexane Isomers Sorption in ZIF-8

$\begin{array}{ccl}\text { ratio of diffusivities } & \text { Herm et al. }{ }^{15 a} & \text { our work }^{a} \\ D_{\mathrm{nC} 6} / r_{\mathrm{c}}^{2} & 0.00833 \mathrm{~s}^{-1} & 0.00488 \mathrm{~s}^{-1} \\ D_{\mathrm{nC} 6} / D_{2 \mathrm{MP}} & 100 & 100 \\ D_{\mathrm{nC} 6} / D_{3 \mathrm{MP}} & 100 & 100 \\ D_{\mathrm{nC} 6} / D_{23 \mathrm{DMB}} & 300 & 150 \\ D_{\mathrm{nC} 6} / D_{22 \mathrm{DMB}} & 300 & 300\end{array}$

${ }^{a}$ Values calculated at $433 \mathrm{~K}$.

Matlab code for a better understanding of the dynamics of sorption of all five hexane isomers in ZIF-8. First, the numerical simulation proves that the $\mathrm{nC} 6$ sorption is essentially equilibrium based while the sorption of branched isomers is kinetically driven. Second, the contact time between the gas and the solid in the bed is extremely important, a very low contact times does not allow enough time for the diffusion of the monobranched isomers $2 \mathrm{MP}$ and $3 \mathrm{MP}$ into the structure of ZIF-8. In addition, branched isomers have very low diffusivities in ZIF-8 due strong intracrystalline diffusional resistances, specially the dibranched ones. Compared to the linear $\mathrm{nC6}$, the diffusivity ratios are $D_{\mathrm{nC} 6} / D_{2 \mathrm{MP}}=D_{\mathrm{nC} 6} / D_{3 \mathrm{MP}}=$ $100, D_{\mathrm{nC} 6} / D_{23 \mathrm{DMB}}=150$ and $D_{\mathrm{nC} 6} / D_{22 \mathrm{DMB}}=300$. Third, in a global view, the results of numerical simulations show that the multicomponent adsorption equilibrium Sips model is reasonably good considering the wide range of experimental conditions studied.

Another important conclusion that can be retained from this study concerns the experimental method used to measure the adsorption equilibrium of hexane isomers in ZIF-8, since experimental data obtained under flow systems or batch equilibrium conditions can be completely different.

Finally, this work proves that, if experimental conditions are carefully setup, especially temperature, residence time, and characteristic time of diffusion, ZIF- 8 is able to completely separate the linear $\mathrm{nC} 6$ from its isomers and partially separate the branched isomers (via kinetic mechanism), making it a promising candidate to be used in total isomerization processes, which is an important result for petrochemical applications involving the octane improvement of gasoline.

\section{ASSOCIATED CONTENT}

\section{S Supporting Information}

The Supporting Information is available free of charge on the ACS Publications website at DOI: 10.1021/acs.iecr.8b05126.

ZIF-8 in shaped form; mathematical model for the simulation of multicomponent breakthrough curves; retention time for the hexane isomers in ZIF-8; model parameters for the simulation of multicomponent breakthrough curves; references (PDF)

\section{AUTHOR INFORMATION}

\section{Corresponding Authors}

*E-mail: adriano_henrique@ipb.pt. Tel.: +351 938144045.

*E-mail: jsilva@ipb.pt. Tel.: +351273 303125.

\section{ORCID}

Adriano Henrique: 0000-0002-5227-9790

Alírio E. Rodrigues: 0000-0002-0715-4761

Notes

The authors declare no competing financial interest.

\section{ACKNOWLEDGMENTS}

We acknowledge financial support from (1) Project ref POCI01-0145-FEDER-016517 (PTDC/QEQ-PRS/3599/2014) funded by FEDER through COMPETE2020 and FCT; (2) AIProcMat@N2020_Advanced Industrial Processes and Materials for a Sustainable Northern Region of Portugal 2020, with the reference NORTE-01-0145-FEDER-000006, supported by Norte Portugal Regional Operational Programme (NORTE 2020), under the Portugal 2020 Partnership Agreement, through the European Regional Development Fund (ERDF), and (3) by Project POCI-01-0145-FEDER006984-Associate Laboratory LSRE-LCM funded by ERDF through COMPETE2020, Programa Operacional Competitividade e Internacionalização (POCI), and by national funds through FCT-Fundação para a Ciência e a Tecnologia.

\section{NOMENCLATURE}

$a_{\mathrm{c}} \quad$ specific area of the column $\left(\mathrm{m}^{-1}\right)$

$a_{\mathrm{p}} \quad$ specific area of the solid $\left(\mathrm{m}^{-1}\right)$

$b_{i}$ adsorption equilibrium affinity constant $\left(\mathrm{bar}^{-1}\right)$

$b_{\infty i}$ frequency factor of the affinity constant $\left(\mathrm{bar}^{-1}\right)$

$C_{i 0}$ gas phase concentration at the inlet of the bed (mol. $\mathrm{m}^{-3}$ )

$C_{i} \quad$ gas phase concentration of sorbate species in bulk phase $\left(\mathrm{mol} . \mathrm{m}^{-3}\right)$

$C_{\mathrm{t}} \quad$ total gas concentration in bulk phase $\left(\mathrm{mol} . \mathrm{m}^{-3}\right)$

$c_{p g}$ heat capacity of gas phase $\left(\mathrm{J} \cdot \mathrm{mol}^{-1} \cdot \mathrm{K}^{-1}\right)$

$c_{p s}$ heat capacity of solid adsorbent $\left(\mathrm{J} \cdot \mathrm{mol}^{-1} \cdot \mathrm{K}^{-1}\right)$

$D_{\mathrm{ax}}$ axial dispersion coefficient $\left(\mathrm{m}^{2} \cdot \mathrm{s}^{-1}\right)$

$D_{c}$ diffusion coefficient of solutes in the porous of the adsorbents $\left(\mathrm{m}^{2} \cdot \mathrm{s}^{-1}\right)$

$D_{\mathrm{m}} \quad$ molecular diffusion coefficient $\left(\mathrm{m}^{2} \cdot \mathrm{s}^{-1}\right)$

$d_{\mathrm{p}} \quad$ particle diameter $(\mathrm{m})$

$E_{\mathrm{Di}} \quad$ activation energy for diffusivity $\left(\mathrm{kJ} \cdot \mathrm{mol}^{-1}\right)$

$F_{i 0}$ molar flow rate of adsorbate species at the inlet of the bed $\left(\mu\right.$ mol.min $\left.{ }^{-1}\right)$

$F_{i} \quad$ molar flow rate of adsorbate species in the bulk gas phase $\left(\mu\right.$ mol.min $\left.{ }^{-1}\right)$

$h_{\mathrm{f}} \quad$ film heat transfer coefficient between gas and solid phase $\left(\mathrm{W} \cdot \mathrm{m}^{-2} \cdot \mathrm{K}^{-1}\right)$

$h_{\mathrm{w}} \quad$ overall heat transfer coefficient at the wall of the column $\left(\mathrm{W} \cdot \mathrm{m}^{-2} \cdot \mathrm{K}^{-1}\right)$

$K_{\mathrm{ax}} \quad$ axial bed thermal conductivity $\left(\mathrm{W} \cdot \mathrm{m}^{-1} \cdot \mathrm{K}^{-1}\right)$

$\mathrm{k}_{\mathrm{LDF}}$ linear driving force mass transfer coefficient $\left(\mathrm{s}^{-1}\right)$

$k_{\text {mix }}$ mixture thermal conductivity $\left(\mathrm{W} \cdot \mathrm{m}^{-1} \cdot \mathrm{K}^{-1}\right)$

$L \quad$ column length $(\mathrm{m})$

$m_{\text {ads }}$ mass of adsorbent in the bed $(\mathrm{g})$

$N$ total number of experiments

$n_{\mathrm{cp}}$ number of components

$n_{i 0} \quad$ heterogeneity index at the reference temperature

$n_{i} \quad$ heterogeneity index

$P \quad$ system total pressure $\left(\mathrm{bar}^{-1}\right)$

$p \quad$ partial pressure $\left(\mathrm{bar}^{-1}\right)$

$p_{\text {TC6 }}$ hydrocarbon total pressure $\left(\mathrm{bar}^{-1}\right)$

$Q \quad$ Isosteric heat of adsorption $\left(\mathrm{kJ} \cdot \mathrm{mol}^{-1}\right)$

$q_{\text {expi }}$ experimental loading $\left(\mathrm{mol} \cdot \mathrm{kg}^{-1}\right)$

$q_{\text {Sipsi }}$ loading predicted by Sips model $\left(\mathrm{mol} \cdot \mathrm{kg}^{-1}\right)$

$q^{*}$ adsorbed phase concentration at equilibrium conditions $\left(\mathrm{mol} \cdot \mathrm{kg}^{-1}\right)$

$\bar{q}_{i} \quad$ average loading in the solid phase $\left(\mathrm{mol} \cdot \mathrm{kg}^{-1}\right)$

$q_{\max }$ maximum saturation loading $\left(\mathrm{mol} \cdot \mathrm{kg}^{-1}\right)$

$R \quad$ ideal gas constant $\left(\mathrm{J} \cdot \mathrm{mol}^{-1} \cdot \mathrm{K}^{-1}\right)$ 
$r_{c} \quad$ crystalline radius $(\mu \mathrm{m})$

$S_{\text {ads }}$ selectivities

$T_{0} \quad$ reference temperature $(\mathrm{K})$

$T$ temperature in bulk gas phase $(\mathrm{K})$

$T_{\mathrm{f}} \quad$ temperature in bulk gas phase at inlet of column $(\mathrm{K})$

$T_{\mathrm{s}} \quad$ temperature of solid phase (K)

$T_{\mathrm{w}}$ temperature of the column wall (K)

$t_{\infty} \quad$ saturation time $(\mathrm{min})$

$t_{\mathrm{rt}}$ retention time $(\mathrm{min})$

$V_{\mathrm{c}}$ adsorption column volume $\left(\mathrm{m}^{3}\right)$

$V_{\mathrm{p}}$ pore volume $\left(\mathrm{cm}^{3} \cdot \mathrm{g}^{-1}\right)$

$v \quad$ interstitial velocity $\left(\mathrm{m} \cdot \mathrm{s}^{-1}\right)$

$v_{\mathrm{s}} \quad$ superficial velocity $\left(\mathrm{m} \cdot \mathrm{s}^{-1}\right)$

$y_{i} \quad$ molar fraction of adsorbate species in bulk phase

$y_{0 i} \quad$ molar fraction of sorbate species at inlet of column

$z \quad$ distance coordinate along fixed bed $(\mathrm{m})$

\section{GREEK LETTERS}

\section{$\alpha \quad$ constant parameter}

$\varepsilon_{\mathrm{b}} \quad$ packed bed porosity

$\rho_{\mathrm{a}} \quad$ apparent adsorbent density $\left(\mathrm{kg} \cdot \mathrm{m}^{-3}\right)$

$\rho_{\mathrm{b}} \quad$ bulk density of solid $\left(\mathrm{kg} \cdot \mathrm{m}^{-3}\right)$

$\theta \quad q_{i} / q_{\text {max }, i}$ fractional loading

$\tau_{\mathrm{fb}} \quad L / v$ residence time in the fixed bed (s)

$\mu_{\text {mix }}$ mixture viscosity $(\mathrm{Pa} \cdot \mathrm{s})$

$\Delta H_{i}$ heat of adsorption $\left(\mathrm{kJ} \cdot \mathrm{mol}^{-1}\right)$

\section{REFERENCES}

(1) Holcombe, T. C. n-Paraffin - Isoparaffin Separation Process. US Patent 4,176,053, 1979.

(2) Holcombe, T. C. Total Isomerization Process, US Patent 4,210,771, 1980.

(3) Cusher, N. A. UOP TIP and Once-Through Zeolitic Isomerization Processes. In Handbook of petroleum refining processes; McGraw-Hill Handbooks: 2004; p 9.299.39.

(4) Minkkinen, A.; Mank, L.; Jullian, S. Process for the Isomerization of $\mathrm{C}_{5} / \mathrm{C}_{6}$ Normal Paraffins with Recycling of Normal Paraffins, US Patent 5,233,120, 1993.

(5) Minkkinen, A.; Deschamps, A.; Cariou, J. P. Process for Isomerizing $\mathrm{C}_{5} / \mathrm{C}_{6}$ Normal Paraffins with Recycling Normal Paraffins and Methyl-Pentanes. US Patent 5,602,291, 1997.

(6) Domergue, B.; Watripont, L. Advanced Solutions for Paraffins Isomerization. In National Petrochemical \& Refiners Association; 2004; pp 1-26.

(7) McCulloch, B.; Lansbarkis, J. R.; Raghuram, S. Extraction of Dimethyl Paraffins from Isomerates. US Patent 5,107,052, 1992.

(8) Dandekar, H. W.; Funk, G. A.; Gillespie, R. D.; Zinnen, H. A.; McGonegal, C. P.; Kojima, M.; Hobbs, S. H. Process for Alkane Isomerization Using Reactive Chromatography. US Patent 5,763,730, 1998.

(9) Dandekar, H. W.; Funk, G. A.; Zinnen, H. A. Process for Separating and Recovering Multimethyl-Branched Alkanes., US Patent 6,069,289, 2000.

(10) Denayer, J.; Ocakoglu, R.; Baron, G. Method for Separating Hydrocarbons and Use of a Zeolite Therefor. US Patent 7.435,865 B2, 2008.

(11) Huddersman, K.; Klimczyk, M. Separation of Branched Hexane Isomers Using Zeolite Molecular Sieves. AIChE J. 1996, 42 (2), 405408.

(12) Huddersman, K.; Klimczyk, M. Separation of Hexane Isomers on Zeolites Mordenite and Beta. J. Chem. Soc., Faraday Trans. 1996, 92 (1), 143-147.

(13) Denayer, J. F. M.; Ocakoglu, R. A.; Thybaut, J.; Marin, G.; Jacobs, P.; Martens, J.; Baron, G. V. N- and Isoalkane Adsorption Mechanisms on Zeolite MCM-22. J. Phys. Chem. B 2006, 110 (17), $8551-8558$.
(14) Mendes, P. A. P.; Ragon, F.; Rodrigues, A. E.; Horcajada, P.; Serre, C.; Silva, J. A. C. Hexane Isomers Sorption on a Functionalized Metal - Organic Framework. Microporous Mesoporous Mater. 2013, 170, 251-258.

(15) Mendes, P. A. P.; Horcajada, P.; Rives, S.; Ren, H.; Rodrigues, A. E.; Devic, T.; Magnier, E.; Trens, P.; Jobic, H.; Ollivier, J.; et al. A Complete Separation of Hexane Isomers by a Functionalized Flexible Metal Organic Framework. Adv. Funct. Mater. 2014, 24 (48), 76667673.

(16) Mendes, P. A. P.; Rodrigues, A. E.; Horcajada, P.; Eubank, J.; Devic, T.; Serre, C.; Silva, J. A. C. Separation of Hexane Isomers on Rigid Porous Metal Carboxylate-Based Metal-Organic Frameworks. Adsorpt. Sci. Technol. 2014, 32 (6), 475-488.

(17) Mendes, P. A. P.; Rodrigues, A. E.; Horcajada, P.; Serre, C.; Silva, J. A. C. Single and Multicomponent Adsorption of Hexane Isomers in the Microporous ZIF-8. Microporous Mesoporous Mater. 2014, 194, 146-156.

(18) Park, K. S.; Ni, Z.; Cote, A. P.; Choi, J. Y.; Huang, R.; UribeRomo, F. J.; Chae, H. K.; O'Keeffe, M.; Yaghi, O. M. Exceptional Chemical and Thermal Stability of Zeolitic Imidazolate Frameworks. Proc. Natl. Acad. Sci. U. S. A. 2006, 103 (27), 10186-10191.

(19) Chang, N.; Gu, Z. Y.; Yan, X. P. Zeolitic Imidazolate Framework-8 Nanocrystal Coated Capillary for Molecular Sieving of Branched Alkanes From Linear Alkanes along with High-Resolution Chromatographic Separation of Linear Alkanes. J. Am. Chem. Soc. 2010, 132 (39), 13645-13647.

(20) Peralta, D.; Chaplais, G.; Simon-Masseron, A.; Barthelet, K.; Pirngruber, G. D. Separation of $\mathrm{C}_{6}$ Paraffins Using Zeolitic Imidazolate Frameworks: Comparison with Zeolite 5A. Ind. Eng. Chem. Res. 2012, 51 (12), 4692-4702.

(21) Dubbeldam, D.; Krishna, R.; Calero, S.; Yazaydin, A. Ö. Computer-Assisted Screening of Ordered Crystalline Nanoporous Adsorbents for Separation of Alkane Isomers. Angew. Chem., Int. Ed. 2012, 51 (47), 11867-11871.

(22) Herm, Z. R.; Wiers, B. M.; Mason, J. A.; Van Baten, J. M.; Hudson, M. R.; Zajdel, P.; Brown, C. M.; Masciocchi, N.; Krishna, R.; Long, J. R. Separation of Hexane Isomers in a Metal-Organic Framework with Triangular Channels. Science 2013, 340 (6135), 960-964.

(23) Ferreira, A. F. P.; Mittelmeijer-Hazeleger, M. C.; Granato, M. A.; Martins, V. F. D.; Rodrigues, A. E.; Rothenberg, G. Sieving DiBranched from Mono-Branched and Linear Alkanes Using ZIF-8: Experimental Proof and Theoretical Explanation. Phys. Chem. Chem. Phys. 2013, 15 (22), 8795-8804.

(24) Zhang, K.; Lively, R. P.; Zhang, C.; Chance, R. R.; Koros, W. J.; Sholl, D. S.; Nair, S. Exploring the Framework Hydrophobicity and Flexibility of ZIF-8: From Biofuel Recovery to Hydrocarbon Separations. J. Phys. Chem. Lett. 2013, 4 (21), 3618-3622.

(25) Chen, L.; Yuan, S.; Qian, J. F.; Fan, W.; He, M. Y.; Chen, Q.; Zhang, Z. H. Effective Adsorption Separation of n-Hexane/2Methylpentane in Facilely Synthesized Zeolitic Imidazolate Frameworks ZIF-8 and ZIF-69. Ind. Eng. Chem. Res. 2016, 55 (40), 1075110757.

(26) Sips, R. On the Structure of a Catalyst Surface. J. Chem. Phys. 1948, 16 (5), 490-495.

(27) Sips, R. On the Structure of a Catalyst Surface. II. J. Chem. Phys. 1950, 18 (8), 1024-1026.

(28) Langmuir, I. The Adsorption of Gases on Plane Surfaces of Glass, Mica and Platinum. J. Am. Chem. Soc. 1918, 40 (9), 13611403.

(29) Freundlich, H. Over the Adsorption in Solution. J. Phys. Chem. 1906, 57 (1), 385-471.

(30) Do, D. D. Adsorption Analysis: Equilibria and Kinetics; World Scientific: 1998; Vol. 2.

(31) Dreisbach, F.; Staudt, R.; Keller, J. U. High Pressure Adsorption Data of Methane, Nitrogen, Carbon Dioxide and Their Ternary Mixture on Activated Carbon. Adsorption 1999, 5 (3), 215-227. 
(32) Schiesser, W. E.; Griffiths, G. W. A Compendium of Partial Differential Equation Models: Method of Lines Analysis with Matlab; Cambridge University Press: New York, 2009.

(33) Schiesser, W. E. wesl's Home Page. 1994; https://www.lehigh. edu/ $\sim$ wes $1 /$. 